University of Rhode Island

DigitalCommons@URI

Open Access Master's Theses

1978

\title{
The Distribution of Hydrocarbons in Narragansett Bay Sediment Cores
}

Andrea Chapin Hurtt

University of Rhode Island

Follow this and additional works at: https://digitalcommons.uri.edu/theses

\section{Recommended Citation}

Hurtt, Andrea Chapin, "The Distribution of Hydrocarbons in Narragansett Bay Sediment Cores" (1978). Open Access Master's Theses. Paper 2117.

https://digitalcommons.uri.edu/theses/2117

This Thesis is brought to you for free and open access by DigitalCommons@URI. It has been accepted for inclusion in Open Access Master's Theses by an authorized administrator of DigitalCommons@URI. For more information, please contact digitalcommons-group@uri.edu. 
THE DISTRIBUTION OF HYDROCARBONS IN NARRAGANSETT BAY SEDIMENT CORES

BY

ANDREA CHAPIN HURTT

A THESIS SUBMITTED IN PARTIAL FULFILLMENT OF THE REQUIREMENTS FOR THE DEGREE OF

MASTER OF SCIENCE

IN

OCEANOGRAPHY

UNIVERSITY OF RHODE ISLAND

1978 


\section{ABSTRACT}

To provide more extensive data on sedimentary hydrocarbons present in Narragansett Bay, twenty cores were collected and analyzed. The results confirmed some expected trends, and also revealed some unusual findings. There was a general decrease in surface sediment hydrocarbon concentration proceeding away from the Providence River toward the mouth of the Bay, and a decrease in hydrocarbon concentration with increasing depth in the sediment cores. However, the East and West Passages of the Bay were quantitatively different. A number of stations in the East Passage showed increasing hydrocarbon concentrations with depth in the cores. From available information, the exact cause of this phenomenon cannot be determined. However, the observed contamination could be due to one or a combination of the following: past Navy activities or unreported spills in that area, previous inputs from the Taunton River, or other factors.

Organic carbon, total hydrocarbon/organic carbon percentages, the concentration of a biogenic hydrocarbon $\left(\mathrm{HC}_{344}\right)$, and the percentage of $\mathrm{HC}_{344}$ /organic carbon in surface sediments were measured and/or calculated to further the understanding of the transport of these substances throughout the Bay. The results indicate that organic carbon generally decreases with distance from the Providence River and with depth in the cores. However, some notable exceptions were found in the East Passage which corresponded to the high hydrocarbon concentrations with depth in these cores. There was a high correlation of total hydrocarbons with organic carbon for surface sediments throughout the Bay. Also, the $\mathrm{HC} / \mathrm{OC}$ percentages generally decreased with increasing 
distance from the Providence River and with depth in the cores, again with some exceptions in the East Passage. A high correlation of the $\mathrm{HC}_{344} / \mathrm{OC}$ percentage in surface sediments with distance down the Bay in the West Passage was observed while there was poor correlation in the East Passage. Finally, there was a poor correlation of $\mathrm{HC}_{344}$ vs the organic carbon in surface sediments for both the East and West Passages.

The information from this study indicates that the main source of hydrocarbons in Narragansett Bay sediments is the Providence River, and that these compounds are probably introduced into the Bay proper via the tidal currents. Previous work has shown that the major source of hydrocarbons in the River is municipal sewage effluents (Van Vleet and Quinn, 1978). These workers have estimated also that approximately 51,000 tons hydrocarbons/year enter U.S. coastal waters via sewage effluents while approximately 25,000 tons/year enter through spills. The present study further substantiates that municipal wastewater treatment plants represent a significant source of oil pollution to estuarine waters. Seeemingly the most efficient way of reducing the input of oil into (and out of) sewage treatment plants would be to institute an oil recycling program. This is becoming more economically feasible with the increasing price of oil. 


\section{ACKNOWLEDGEMENTS}

Reflecting on the people and experiences of the past three years, I remember not only the "blood, sweat, and tears" of experiments gone wrong and the agonies of writing, but also the laughter and the sharing of good times. To those people of the gang in particular: Evelyn Dyer for speedy typing and a willing ear; Eva Hoffman for a sometimes confidante and mutual going to bat; Dick Kerr for his blushing laugh; Gary Mills for his cake and encouragement during the training for the Guiness Book of records for the most vials lost during organic carbon analyses; Ted Van Vleet for quiet helpful ways; Terry wade for patient instruction and deftness at egging me on; Harlow for keeping me Taughing when I most needed it; Big Red for giving me a kick when necessary; and last but by no means least, Jim Quinn, the best of advisors who through experiment has been shown to be uninterested in the MCP reaction. And to all those others who survived my "expoundations". 


\section{PREFACE}

This thesis is written in manuscript form according to the rules of the Graduate School of the University of Rhode Island. It consists of one manuscript and two appendices.

The manuscript, to be submitted to Environmental Science and Technology, deals with the qualitative and quantitative distribution of hydrocarbons in sediments from Narragansett Bay. Appendix I deals with the possibility of Mercenaria mercenaria fecal material being the source of $\mathrm{HC}_{344}$. The results indicate that the fecal material is not the source of this hydrocarbon in Narragansett Bay sediments. Appendix II is a compendium of the data from the 20 sediment cores taken in Narragansett Bay. 


\section{TABLE OF CONTENTS}

$\underline{\text { Page }}$

PREFACE ................... $i$

LIST OF TABLES ........................ . . . . .

LIST OF FIGURES ..................... iv

THE DISTRIBUTION OF HYDROCARBONS IN NARRAGANSETT BAY SEDIMENT CORES

Introduction ............... . .

Literature Review............... 3

Materials and Methods .............. . 13

Results ................. . . 19

Discussion . . . . . . . . . . . . 34

Acknowledgements . . . . . . . . . . 4 48

References .............. . 49

APPENDICES

APPENDIX I

$\mathrm{HC}_{344}$ in Mercenaria mercenaria Fecal Material . . . .56 APPENDIX I I

Compendium of Hydrocarbon Data from Twenty

Sediment Cores in Narragansett Bay . . . . . . . 59 


\section{LIST OF. TABLES}

Page

THE DISTRIBUTION OF HYDROCARBONS IN NARRAGANSETT BAY

SEDIMENT CORES

1. Total Hydrocarbon Concentrations and Percent

Resolved Hydrocarbons with Depth at Stations

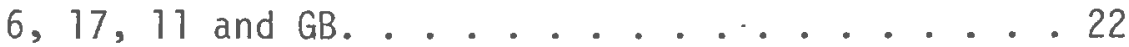

2. Concentration of $\mathrm{HC}_{344}$, Organic Carbon, and Percentage of Organic Carbon as Total Hydrocarbon with Depth at Stations 6, 17, 11 and GB . . 24 APPENDICES

APPENDIX I

1. Comparison of Hydrocarbon Analyses of Surface

Sediments $(0-5 \mathrm{~cm})$ and Fecal Material from

Mercenaria mercenaria . . . . . . . . 58

APPENDIX II

1. Compendium of Hydrocarbon Data from Twenty

Sediment Cores in Narragansett Bay . . . . . . . 60 


\section{LIST OF FIGURES}

Page

THE DISTRIBUTION OF HYDROCARBONS IN NARRAGANSETT BAY

SEDIMENT CORES

1. Narragansett Bay and Locations of Sampling Stations . . . . 14

2. Hydrocarbon Concentrations with Depth in the Sediments

of the West Passage vs Distance from the Providence

River....................... 20

3. Hydrocarbon Concentrations with Depth in the Sediments

of the East Passage vs Distance from the Providence

River....................... 21

4. Percentage of Organic Carbon as Total Hydrocarbon in the

East and West Passages with Distance from the Providence

River to the Mouth of Narragansett Bay

(Surface Sediments, $0-5 \mathrm{~cm}$ ) . . . . . . . . . . 26

5. Percentage of Organic Carbon as $\mathrm{HC}_{344}$ in the East and West Passages with Distance from the Providence River

to the Mouth of Narragansett Bay (Surface Sediments, 0-5 cm). 28

6. Relationship of $\mathrm{HC}_{344}$ to Organic Carbon in Surface

Sediments $(0-5 \mathrm{~cm})$ of Narragansett Bay . . . . . . . . 29

7. Relationship of Total Hydrocarbons of Sediments in East

and West Passages to its Organic Carbon Content . . . . 30 
8. Gas Chromatograms (Packed Columns) of Hydrocarbons in Sediment Core from Station 6......... . . 32

9. Gas Chromatogram (Glass Capillary) of Hydrocarbons in PENNANT Oi] Sample (a) and in Sediment Core

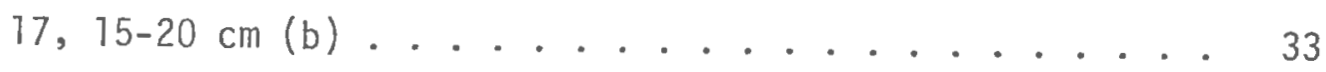




\section{INTRODUCTION}

The recent rash of oil tanker disasters off the New England coast and elsewhere has re-emphasized the problem of oil pollution in the marine environment. Although accidents such as the ARGO MERCHANT are big news, there are other sources of oil pollution that contribute as much or more $0 i 1$ to the estuarine and coastal zone. A recent NAS Report (1975) estimated that only about 3\% of the petroleum hydrocarbons introduced into the oceans annually is from tanker accidents while $26 \%$ is from river runoff, and $10 \%$ each is from atmospheric fallout and natural seeps. The remaining inputs include urban runoff $(5 \%)$, municipal wastes $(5 \%)$, industrial wastes $(5 \%)$, transportation $(32 \%)$, coastal refineries (3\%), and offshore production (1\%).

It has been only during the past several years that published reports on petroleum pollution in Narragansett Bay have been available. The samples analyzed included sewage effluent, water,clams, and sediments, but the extent and nature of these samples have varied. For example, in most cases, only the surface sediments (approximately $0-10 \mathrm{~cm}$ ) have been analyzed for hydrocarbons. Sampling areas have been concentrated in the Providence River and West Passage (Farrington and Quinn, 1973a,c; Schultz and Quinn, 1977; Van Vleet and Quinn, 1977), Rhode Island Sound (Boehm and Quinn, 1978), and Quonset Point (Franklin and Brown, 1977). One of the major problem areas is the sewage treatment plants, especially the Fields Point Plant which contributes approximately $46 \%$ of the total sewage discharge entering Narragansett Bay, and about $71 \%$ that enters the Bay from the Providence River (Van Vleet and Quinn, 1977; Schultz, 1974). 
With an average hydrocarbon concentration of $2.8 \mathrm{mg} / 1 \mathrm{iter}$, this plant discharges approximately 226 metric tons of hydrocarbons into the Providence River each year (Van Vleet and Quinn, 1977). Other areas of concern are Quonset-Davisville (Franklin and Brown, 1977), other sites previously occupied by the Navy (e.g. Prudence Island and Melville), concentrated population locations where runoff can have higher than normal petroleum levels (e.g. Providence), and sites where previous oil spills have occurred (e.g. Popasquash Point).

The present study involves a detailed investigation of the distribution of biogenic and anthropogenic hydrocarbons in sediment cores from various depositional environments of Narragansett Bay. The sampling of the Bay is much more extensive, both in number of sites and in the depth of the cores, than previously attempted. The information obtained from this investigation will be helpful in evaluating current and potential petroleum related activities in the Bay, and serve as a baseline on which decisions concerning future uses can be made. The results can be useful not only for Narragansett Bay, but also for other estuarine and coastal areas that face similar problems. Furthermore, from a geochemical standpoint, the results aid in understanding the transport and fate of petroleum hydrocarbons throughout Narragansett Bay. 


\section{LITERATURE REVIEW}

Hydrocarbon Sources

Hydrocarbons in the marine environment occur both naturally and as a result of pollution by man. Since the industrial revolution, man's use of petroleum as an energy source has increased and has grown dramatically over the last 100 years (Hottel and Howard, 1971). Subsequently, there has been an increase in hydrocarbon pollution. A recent summary of estimates for worldwide petroleum sources and inputs to the marine environment (Van Vleet and Quinn, 1978) concludes that there are four principle inputs: 1) oil production operations; 2) land-based discharges other than those directly related to $0 i 1$ production; 3 )natural oil seeps; and 4) atmospheric deposition. As pointed out by these authors and by Hardy et a1. (1977), the quantity and size of the different inputs vary substantial1y. Nevertheless, Hardy et a1. (1977) claim that the total petroleum input is probably between $10^{6}$ to $10^{7}$ tons/year.

This concern over the fates and effects of oil in the marine environment has produced an increased level of research in the hydrocarbon chemistry of water, sediments, and organisms (B7umer, 1970; Evans and Rice, 1974; Sutterlin, 1974). In terms of looking at the distribution of petroleun hydrocarbons throughout the marine environment, it is believed that the "analysis of sediments and benthic fauna may better indicate the extent of some types of estuarine pollution than the analysis of the water column and neretic or planktonic organisms since the former have a greater probability of concentrating pollutants" (Farrington, 1971). From a number of studies done on the fate of $0 i 1$ 
introduced into the marine environment (NAS 1973, 1975; API 1971, 1973, 1975), it is evident that oil incorporated into the sediments may have a lasting or extended effect on the surrounding ecosystem. Therefore, the estimation of the amount of hydrocarbons in the sediment, as well as the rate at which they are being added, is fundamental to understanding the impact of oil pollution on the marine environment. The levels of hydrocarbons found in the sediments may vary from $0-4$ $\mathrm{mg} 0 i 1 / \mathrm{kg}$ dry sediment in very deep water to over $1 \mathrm{~g} \mathrm{oil} / \mathrm{kg}$ in : polluted inshore sediments (NAS, 1975).

Hydrocarbons enter the marine environment via three general processes (Farrington and Meyers, 1975):

1) biosynthesis- marine and land organisms biosynthesize hydrocarbons either de novo or from ingested precursor compounds;

2) geochemical processes- submarine and coastal 1and oi 1 seeps, weathering of soils and sediments, chemical synthesis processes (forest fires, diagenesis of organic matter in sediments);

3) anthropogenic inputs- from accidental and intentional discharge of fossit fuel to the marine environment and atmosphere.

In the analysis of sedimentary hydrocarbons, one must be able to deal with the entire spectrum of oils and oil products at both high and low concentrations as well as with natural (biogenic and geochemical) hydrocarbons. The estimation of petroleum hydrocarbon composition and concentration is complicated by the complex mixture of compounds in petroleum which have wide molecular weight and polarity ranges, and by the interplay of the above-mentioned processes. These sources must be 
differentiated when determining the amount contributed by petroleum hydrocarbons. Fortunately, there are sufficient differences between the composition and structure of the natural and pollution-derived hydrocarbons to permit their individual detection if properly sensitive analytical methods are used. Many papers discuss the various hydrocarbons, their sources and chemical methods of analysis (Farrington et al.,1976; Farrington and Meyers, 1975; Eglinton et a1., 1975).

Compared to petroleum, biogenic hydrocarbons have narrow molecular weight and molecular structure ranges(Blumer et al.,1972; NAS, 1975). Also, olefins which are abundant in most marine organisms are not usually found in refined petroleum products. In the case of biogenic hydrocarbons, the straight chained, saturated and olefinic compounds predominate while the branched chain hydrocarbons, especially the isoprenoid alkanes and alkenes formed by marine organisms, cover a narrow molecular weight range. Petroleum shows a more complex mixture of hydrocarbons, not found so extensively in organisms, and often referred to as the "hump" (Eglinton et a1., 1975). This unresolved complex mixture (UCM) results from the co-elution of cycloalkanes, aronatic hydrocarbons and naphtheno-aromatics. Farrington et a1. (1977) believe that the UCM signal in a gas chromatogram may be a clue to the presence or absence of petroleum pollution. Furthermore, petroleum contains many homologous series where adjacent members of a series are present in nearly the same concentration (odd/even ratio of $n$-alkanes ( 1); whereas, in organisms this is not usually the case (odd/even ratio is substantially greater than one). For example, in marine phytoplankton the $n$-alkanes with $15,17,19$ and 21 carbons are most abundant (B1umer et a1., 1971); whereas, in marsh grasses and Sargassum 
21-29 carbon n-alkanes predominate (Burns and Teal, 1973).

Sedimentary Hydrocarbon Studies - An Overview

In the past, much of the focus on oil pollution has been on the effects of direct inputs, mainly from tanker operations and spills. Hyland (1977) recently published a report on polluting incidents in and around New England that is useful in identifying areas where direct one-time injections have occurred. Presently, many investigators are looking at the more chronic inputs of hydrocarbons to the marine environment, i.e. industrial and municipal wastes. Wakeham (1976) examined sediments from three lakes in western washington to compare petroleum contamination. He found that the differences in hydrocarbon distribution in the cores could be related to the degree of human activity in the drainage basins; 1) high level petroleum contamination in a lake surrounded by a large metropolis; 2) moderate contamination of a suburban-rural 1ake; and 3) apparent absence of detectable contamination in a control lake in a national park. The evidence strongly suggests that the most likely source for hydrocarbons in the uncontaminated sediment is terrigenous plant detritus from rivers and streams. The hydrocarbons found in the other two lakes were petroleum in nature (Wakeham and Carpenter, 1976; Wakeham, 1977 ) with the source being urban stormwater runoff. The other possible sources such as spills and sewage effluents were eliminated as not probable in these cases.

Giger et a1. (1974) examined sediments from Lake Zug, Switzerland and found that sediments near the densely populated northern shores contain large amounts of hydrocarbons, predominantly derived from fossil 
fuels; the indigenous hydrocarbons, presumabiy derived from aquatic organisms and from land material transported by the River Lorze, predominated in the middle part of the lake farther away from the polluted area.

Another investigator (Shaw, 1973) analyzed sediments from the bottom of Boston Harbor and vicinity for lipids. Un1ike some other reports (BTumer and Sass, 1972; Farrington and Quinn, 1973a) where there was a general decrease in hydrocarbons away from the site of injection, Shaw found highly fouled sediments in close proximity to relatively clean ones. He postulated that the uneven and irregular distributions were due in part to the multiplicity of pollution sources in the harbor. These sources (Ducsik, 1971) include discharge of treated sewage at the mouth of the harbor, raw sewage from malfunctioning and overflowing combined sanitary waste and storm runoff, sewer relief points, and petroleum spillage. Other contributing factors to the uneven distributions were mechanisms of adsorption of organic matter onto sediments, and more importantly the tidal currents.

Walker et a1. (1975) examined sediment cores from the Baltimore Harbor of Chesapeake Bay. This area receives a continuous input of $0 i 1$ pollutants such as tank washings, accidental spil1s, sewage effluent and 7 and runoff (Wegener, 1973). Also, dredge spoils from the harbor are deposited in deeper water of the bay. Core samples from colgate Creek showed a decrease in hydrocarbons with depth in the sediment, and that petroleum hydrocarbons entering Chesapeake Bay via Colgate Creek are partially degraded with the residual material accumulating in the sediment layers. The information gained from this study was that the biodegradation demand of the biota of the recipient site for the dredge 
spoils is greater than at the original input site since only the more refractory components of the petroleum hydrocarbons are present at the spoil site.

Narragansett Bay

With the realization that chronic pollution could be more devastating on the marine environment than one-time disasters, researchers have devoted increasing amounts of time to the study of continuous pollution. Narragansett Bay is such an area. According to information from the Rhode Island Department of Health (1975), Narragansett Bay receives chronic discharge from various sources: sewage treatment plants, storm sewers, manufacturers, dye and worsted mills, and other industries. These are in addition to the wastes from boating and shipping activities, smalt and Targe oit spills, and urban air fallout from fossil fuel combustion products. The discharges may contain metals, petroleum hydrocarbons, bacteria, viruses, and a host of chemicals. Goldberg et al. (1977) looked at the heavy metal pollution of Narragansett Bay sediments. They reported that the historical records of pollutant fluxes can allow predictions of future concentration levels in estuarine waters. Along similar Tines, Farrington and Quinn (1973a) analyzed hydrocarbons in surface sediments and in Mercenaria mercenaria. They found a very complex mixture of hydrocarbons which, among other indicators, strongly suggested that the samples were contaminated by petroleum hydrocarbons. Furthermore, the contamination appeared to result from the discharge of petroleum hydrocarbons in sewage effluents and from smalt oil spills. Zafiriou (1973) conducted a detailed chemical examination and ${ }^{14} \mathrm{C}$ determination to characterize 
the sedimentary hydrocarbons and identify their most probable source. His findings were consistent with a predominantly petroleum origin for these hydrocarbons. Sewage effluents and small oil spills discharged to Narragansett Bay may be chemically modified by evaporation, dissolution, and partial biochemical oxidation to yield the observed hydrocarbon distribution in these sediments.

Kremer and Nixon (1978) developed a hydrodynamic model for Narragansett Bay that simulates currents, flow rates, and flushing times throughout the system. This model can be useful in the prediction of the effects of storms, the fate of pollutants, and the dynamics of ecological systems. Among other capabilities, the model has been modified to simulate the movement of oil slicks (Premack and Brown,1973). Schultz and Quinn (1977) found that the fatty acid and hydrocarbon composition of the suspended material (20 $\mathrm{cm}$ below water surface) were similar to those of sediment at the same stations (Farrington and Quinn, 1973a,b), and showed a trend of decreasing concentration away from the Providence River. Values for suspended hydrocarbons from one station in the Providence River were put into the gross scale hydrodynamic model of Kremer and Nixon (1978) to estimate concentrations in other sections of the Bay. There was excellent agreement between the results of the model and the observed hydrocarbon concentrations (correlation coefficient 0.998 ) which suggests that the major source of suspended hydrocarbon input into Narragansett Bay is in the Providence River. Furthermore, the model indicated that sedimentation as well as dilution are important processes in lowering the hydrocarbon concentrations in the Bay.

Oviatt and Nixon (1975) collected sediments in traps one meter 
above the sediment surface. There was an increase in sediment activity, e.g. settlement, from the head to the mouth of the estuary. Also, the deposited materials were higher in total organic matter, organic carbon, and nitrogen than near surface sediments on the bottom and showed a decrease toward the mouth of the Bay. These results may be misleading since the analysis of the top $4 \mathrm{~cm}$ of the core included a large amount of inactive sediment that could have lowered the values. Furthermore, the deposited materials were for the most part resuspended bottom sediments rather than fresh inputs of material from the water column. Narragansett Bay has relatively small inputs of terrestrial sediment and has little fresh water input. Therefore, the amount of suspended material in the water and the rate of sediment accumulation generally appears low. Tidal currents, in addition to deposit feeding infauna which rework the sediment making it more subject to resuspension, are probably responsible for most of the sediment activity.

Farrington and Quinn (1973c) collected sewage effluents from West Warwick, East Providence, and the Fields Point plant to determine the presence and quantities of fatty acids and hydrocarbons. The results indicated that appreciable amounts of petroleum hydrocarbons were being discharged and that this would be a major source of petroleum hydrocarbons found in sediments and clams from the Bay.

Van Vleet and Quinn (1977) expanded the study on the effect of the discharge from the Fields Point sewage treatment plant, the largest in Rhode Island discharging $46 \%$ of the total sewage volume into the Bay, and $71 \%$ entering from the Providence River (R.I. Dept. of Health, 1975; SchuTtz, 1974). They reported that about 226 metric tons of hydrocarbons/ year are discharged from this plant. Water and sediment samples taken in the Providence River and at the head of Narragansett Bay indicated 
that approximately $50 \%$ of the suspended hydrocarbons are rapidly sedimented out in the River and accumulate in the sediments. The remainder of the hydrocarbons are transported down river via the tidal cycle and undergo gradual sedimentation throughout the Bay. Some calculations on national petroleum wastes from sewage indicate that approximately 51,000 tons/year are discharged in U.S. coasta1 waters; whereas, approximate1y 25,000 tons enter U.S. coastal waters from direct spills annual1y (USCG 1975, 1976). This illustrates that the municipal wastewater treatment plants can represent a significant source of $0 i 1$ pollution to coastal waters (Van Vleet and Quinn, 1978).

Boehm and Quinn (1978) investigated the spatial distribution of hydrocarbons in upper Rhode Island Sound surface sediments and in Arctica islandica to distinguish the regular hydrocarbon geochemistry of Rhode Island Sound, defined by background hydrocarbon distributions and inputs from Narragansett Bay and adjacent coastal areas, from the input due to hydrocarbons from deposited dredge spoils. The Rhode Island Sound sedimentary hydrocarbons have fewer quantities of low boiling resolved and unresolved features than those from the Providence River adjacent to the outfall which are typical of the Fields Point sewage treatment plant. Furthermore, sediments from Narragansett Bay proper (Farrington and Quinn, 1973a; Van Vleet and Quinn, 1977; Wade and Quinn, 1978a) indicate that the lower boiling components are rapidly lost through weathering and an assembleage similar in boiling point distribution to Rhode Island Sound sediment is found in the Bay and elsewhere in the Providence River.

In a study on a few sediment cores from Narragansett Bay and Rhode 
Island Sound, Van Vleet and Quinn (1978) determined that the total hydrocarbons decreased with distance away from the Providence River and with depth in each core. Also, the percentage of resolved (n-alkanes and branched alkanes) hydrocarbon components showed a general increase progressing away from Narragansett Bay and downcore at each station. Compared to the Gulf of Maine (25\%), the Rhode Island Sound sediments and Narragansett Bay sediments show a smaller percentage of resolved components $(5 \%)$ and the Providence River even less (0\%) (Van Vleet and Quinn, 1978), indicating the greater extent of anthropogenic hydrocarbons distributed throughout the Providence River, Narragansett Bay, and Rhode Island Sound coastal sediments. Also evident were the biogenic alkanes $\mathrm{nC}_{25}, \mathrm{nC}_{27}, \mathrm{nC}_{29}$ and $\mathrm{nC}_{37}$. Both land and marine organisms synthesize $n$-alkanes. Marine phytoplankton have a predominance of 15, 17, 19 and 21 carbon atoms; whereas, in marsh grasses and Sargassum 21-29 odd carbon n-alkanes predominate (Farrington and Meyers, 1975). The biogenic n-alkanes found in the sediments are believed to be continentally derived from higher plants and probably act as a waxy outer protective layer. In association with the lignin-cellulose plant matrix, these hydrocarbons are apparently resistant to degradation in the sediments. The concentration of these biogenic hydrocarbons has been shown to remain relatively constant throughout the top 40 to 50 cm of estuarine sediments (Boehm and Quinn, 1978; Farrington et a)., 1977; Wade and Quinn, 1978a). 


\section{MATERIALS AND METHODS}

\section{Sampling and Extraction}

Sediment cores from 20 stations in Narragansett Bay (Figure 1) were taken during 1976-1977 aboard the R/V BILLIE II and the R/V DULCINEA. Also included in Figure 1 are stations 1-4 in the Providence River (Van Vleet and Quinn, 1977). A gravity corer with a $40 \mathrm{~kg}$ weight was used to obtain core samples ranging in depth from 20-60 cm and from water depths of 5-55 m. The samples were stored in the core 1 iners at $-20^{\circ} \mathrm{C}$ until analyzed. The plastic core liners were a possible source of contamination so upon extrusion of the sediment, the areas in contact with the liner were scraped and discarded. The samples were divided into $5 \mathrm{~cm}$ sections and placed in glass jars previously washed with distilled solvents.

A thawed subsample of each section ( $1-5 \mathrm{~g})$ was dried at $105-115^{\circ} \mathrm{C}$ for two hours to determine the moisture content. At the outset, the samples were wet sieved with, distilled water, sieved through a $1 \mathrm{~mm}$ brass screen and vacuum filtered through a Whatman 90 filter. The wet sieving removes both shell fragments and any macrofauna, and also insures a relatively homogenous sample. Later in the experiment, the wet sieving was discontinued because of the time required for this procedure. Analysis of sieved and un-sieved sediment samples indicated that there was no statistical difference in the hydrocarbons results obtained by these two methods (T.L. Wade, personal communication). Depending on the estimated hydrocarbon content of the sample, a 30-60 g dry weight subsample was placed in a $500 \mathrm{ml}$ round bottom flask 
Figure 1. Narragansett Bay and locations of sampling stations. C - Conanicut Island L - Wickford M-Melville P - Prudence Is I and Q-Quonset-Davisville S - Sand Point Cove 


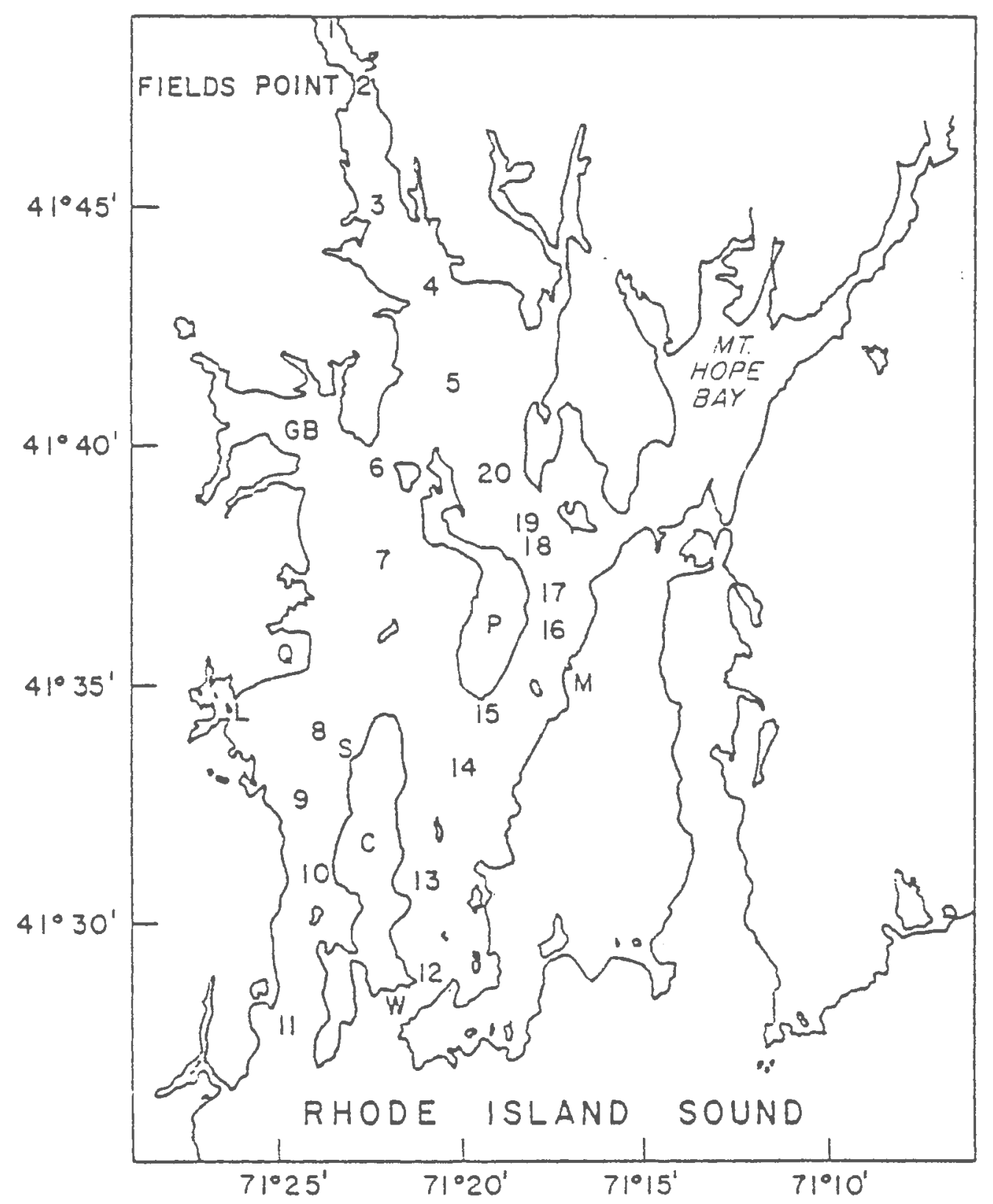


and $n C_{20}$ (n-eicosane) and/or $n C_{22}$ (n-docosane) were added as internal standards.Approximately $1-3 \%$ of the estimated total hydrocarbon content of the sample was the general gauge for the amount of internal standard used in each analysis. Where the hydrocarbon value of the sample was difficult to estimate, two internal standards were used to bracket the possible ranges. Based on the calculated dry weight of the sediment, a 5 -fold volume excess of solvent mixture $(70 \% 0.5$ $\mathrm{N} \mathrm{KOH}$ in absolute methanol and $30 \%$ toluene) was added to the sample. If necessary, distilled water was added to give between 10 and $20 \%$ water relative to the total volume of methanol, distilled water and sediment water to prevent transesterification reactions. Where the amount of water exceeded $20 \%$, the appropriate proportional amounts of $\mathrm{KOH} /$ methanol and toluene were added to lower the $\%$ water in the mixture. The sediment-solvent mixture was then refluxed for two hours.

After extraction, the cooled mixture was filtered through a pre-ignited ( 4 hours at $450^{\circ} \mathrm{C}$ ) Whatman $\mathrm{GF} / \mathrm{C}$ glass fiber filter, and washed with methanol $(20-50 \mathrm{ml})$ and petroleum ether $(20-50 \mathrm{ml})$. The filtrate and washings were combined in a separatory funnel and distilled water was added to give 2 phases (saponifiable fraction in the water/ methanol phase-bottom, and non-saponifiable fraction in the toluene/ petroleum ether phase-top). The amount of distilled water added was at 1 east $50 \%$ of the total amount of methanol present. The mixture was shaken, allowed to separate and the toluene/petroleum ether phase was isolated. The water/methanol phase was extracted 2 additional times with petroleum ether using at least a $10 \%$ volume relative to the water/ methanol phase. The resulting 3 extracts were combined and evaporated to dryness under vacuum on a rotary evaporator at $40^{\circ} \mathrm{C}$ or less, adding 
methanol to azeotrope the toluene, if necessary.

\section{Chromatographic Processes}

Prior to Thin Layer Chromatography (TLC), a column chromatography cleanup procedure was used to remove most of the polar, nonhydrocarbon organic material and elemental sulfur form the nonsaponifiable extract (Van Vleet and Quinn, 1977). The extract (in $1 \mathrm{~m}$ ] of $95 / 5$ petroleum ether/toluene) was applied to a $6 \mathrm{~mm}$ i.d. column containing $1 \mathrm{~g}$ of alumina (deactivated with $5 \%$ distilled water) over copper powder (activated with $3 \mathrm{~N} \mathrm{HCl}$ ) and eluted with 5 bed volumes ( $5 \mathrm{ml}$ ) of the $95 / 5$ mixture. The eluted fraction contained alkane, olefinic and aromatic hydrocarbons leaving most of the polar material adsorbed to the alumina. The column eluate was evaporated to dryness in preparation for TLC isolation.

TLC plates $(20 \times 20 \mathrm{~cm})$ were prepared using Silica Ge $\mathrm{G}(0.37 \mathrm{~mm})$, activated for 1 hour at $100-110^{\circ} \mathrm{C}$, and predeveloped in chloroform/ methanol $(80 \mathrm{ml} / 20 \mathrm{ml})$ for 4 hours. The plates were then spotted with standards $\mathrm{nC}_{26}$ and phenanthrene (in chloroform or dichloromethane). The sample was dissolved in chloroform or dichloromethane and applied to the Silica Gel plate. The developing system was petroleum ether $/ \mathrm{NH}_{4} \mathrm{OH}$ $(100 \mathrm{ml} / 1 \mathrm{ml})$. The total hydrocarbon band, corresponding to chromatographed $\mathrm{nC}_{26}$ and phenanthrene hydrocarbon spotting standards, was visualized by spraying with bromothymol blue indicator, scraped from the plate and extracted with chloroform or dichloromethane. The sample was evaporated under vacuum and analyzed by gas liquid chromatography (GLC).

Later in the experiment the column/TLC procedure was modified: the column was prepared in a Pasteur pipette containing (bottom to top) a glass wool plug, $0.3 \mathrm{~g}$ copper powder (activated with $3 \mathrm{~N} \mathrm{HCl}$ ), $1 \mathrm{~g}$ 
of silica gel (deactivated with $5 \%$ distilled water), $1 \mathrm{~g}$ of àiumina (deactivated with $5 \%$ distilled water), and another glass wool plug. The sample was charged to the column in $1 \mathrm{ml}$ of $95 \%$ petroleum ether $/ 5 \%$ toluene mixture and was eluted with $15 \mathrm{ml}$ of the $95 / 5$ mixture. It was found that this column procedure retained elemental sulfur, methil esters, methy 1 ketones and more polar organic compounds while eluting hydrocarbons including $n$-alkanes and aromatics such as phenanthrene, pyrene, and chrysene (Hoffman and Quinn, 1978). The sample was analyzed by GLC as discussed below.

Each sample was dissolved in dichloromethane and analyzed on HewlettPackard Models 5750 or 5711 gas chromatographs equipped with dual flame ionization detectors and dual $2 \mathrm{~m} \times 2.2 \mathrm{~mm}$ i.d. stainless steel packed columns containing either 5\% FFAP on Chromosorb W(HP), 80/100 mesh or $10 \%$ SP-1000 on Supelcoport, $80 / 100$ mesh. The columns were temperature programmed from $90-250^{\circ} \mathrm{C}$ or $260^{\circ} \mathrm{C}$ at $8^{\circ} / \mathrm{min}$. The hydrocarbons measured eluted in the range of $n C_{14}-n C_{34}$ and were quantified by comparing them to the areas of the internal standards $\mathrm{nC}_{20}$ or $\mathrm{nC}_{22}$ as measured by planimetry. Also, a few selected samples were analyzed on a HewlettPackard Model 5840A gas chromatograph (flame ionization) equipped with a glass capillary column ( $15 \mathrm{~m}, 0.25 \mathrm{~mm}$ i.d.,0V-101, Quadrex Co.). Temperature programming was from $90-240^{\circ} \mathrm{C}$ at $4^{\circ} / \min$ (Dr. Eva Hoffman, personal communication).

\section{Solvents, Blanks and Precision}

A11 solvents were either glass distilled ACS Reagent Grade or Nanograde solvents. Procedural blanks were determind by carrying solvents and internal standard(s) through the analytical procedure in the absence of sediments. In general, the procedural blanks were analyzed with the bottom sections of the core $(15-30 \mathrm{~cm})$. The values for the top sections 
of the core $(0-15 \mathrm{~cm})$ ranged between 7 and 670 times above the blank and averaged 139 times the blank. The lower sections of the core $(15-30 \mathrm{~cm})$ ranged between 1.5 and 621 times above the blank with an average of 87 times the blank. The reported sample values have been corrected for the blank. The precision ( \pm 1 standard deviation) of the analytical method and chromatographic analysis is $\pm 5 \%$. Subsampling (separate subsamples from the same grab section) precision is approximately $\pm 16 \%$ (Wade and Quinn, 1978b) while results from replicate samples from the same station can vary $\pm 26 \%$ (Boehm and Quinn, 1978).

\section{Organic Carbon Analysis}

Sediment samples were analyzed for organic carbon using a new procedure (Mi11s and Quinn, 1978) based on the persulfate oxidation method of Menzel and Vaccaro (1964). Sediment subsamples were dried at $100-110^{\circ} \mathrm{C}$ for $3-5$ hours, ground to a fine powder, weighed on a Cahn Electrobalance and transferred into $10 \mathrm{ml}$ ampoules. The samples $(0.5-5 \mathrm{mg})$ were acidified with $5 \mathrm{ml}$ of $1 \mathrm{~N} \mathrm{H}_{3} \mathrm{PO}_{4}$ and sonicated for $1 / 2$ hour. This step removes inorganic carbonates and helps remove organic matter from the mineral matrix. Potassium persulfate and deionized water (Super-Q) were added to the sample followed by purging with $\mathrm{N}_{2}$ for approximately 6 minutes. The ampoules were sealed with a propane torch, oxidized at $110^{\circ} \mathrm{C}$ for 3 hours and then were analyzed on an Organic Carbon Analyzer (Oceanography International Model 0524A). Standards, standard blanks, and sample blanks were also analyzed. The sample blanks ranged from 3 to $10 \mu \mathrm{g}$ carbon, and the samples were 2-10 times above the blanks. The overall precision for the procedure was about $10 \%$. 


\section{RESULTS}

Figures 2 and 3 illustrate the concentration of total hydrocarbons in sediment cores with distance from the mouth of the Providence River to the mouth of Narragansett Bay. Station 5 is 1 isted in both figures to provide a comparison of the trends for the East and West Passages. The samples, although analyzed in $5 \mathrm{~cm}$ sections down to $30 \mathrm{~cm}$ in most cases, are shown as the individual top 4 sections and the combined bottom 2 sections. This approach facilitates the interpretation of the data since in general the hydrocarbon concentrations in the bottom 2 sections of the core were small compared to the top sections with the exception of a few stations in the East Passage. As can be seen, there are striking differences between the East and West Passage trends. The West Passage stations (Figure 2) show a general decrease in total hydrocarbon concentration as one proceeds down the Bay and also with depth in the sediment cores. Other investigators (Van Vleet and Quinn, 1977, 1978; Farrington and Quinn, 1973a) have seen similar results although the sampling was not as extensive as in this study. In contrast to the West Passage, the East Passage stations (Figure 3 ) do not show the above two trends. In the discussion section, some hypotheses for these observations will be presented.

Table 1 compares total hydrocarbons and \% resolved hydrocarbons (n-alkanes and branched alkanes) for 4 different stations in Narragansett Bay. Station 6 is more representative of upper Bay values, and is also informative since this core extends to $50 \mathrm{~cm}$ rather than the usual 30 $\mathrm{cm}$. Station 17 (mid-East Passage) shows the unexpected trend of increasing hydrocarbon concentration with depth in the core and the 
Figure 2. Hydrocarbon concentrations with depth in the sediments of the West Passage vs distance from the Providence River. 


\section{TOTAL HYDROCARBON CONCENTRATION}
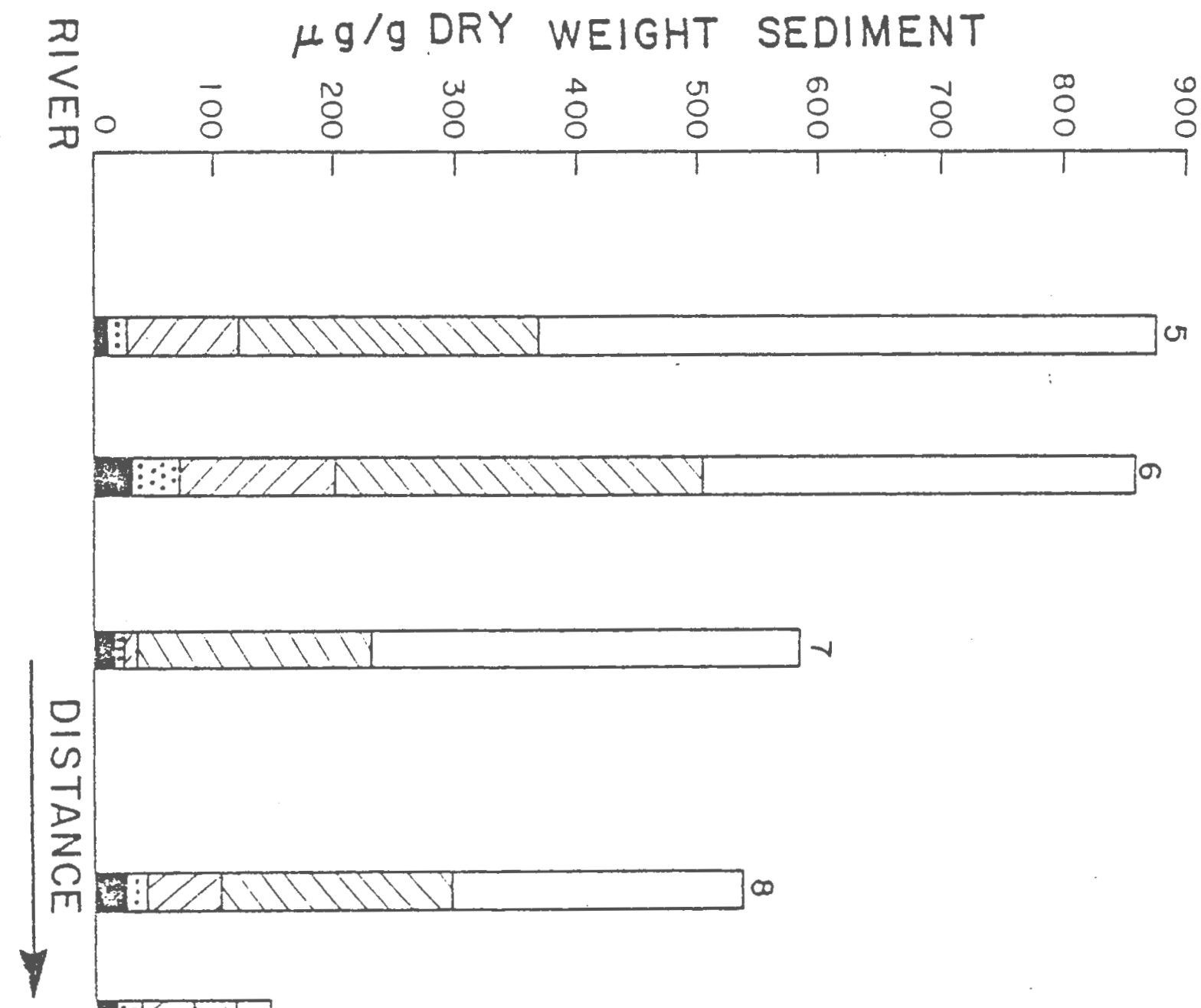

\section{:}

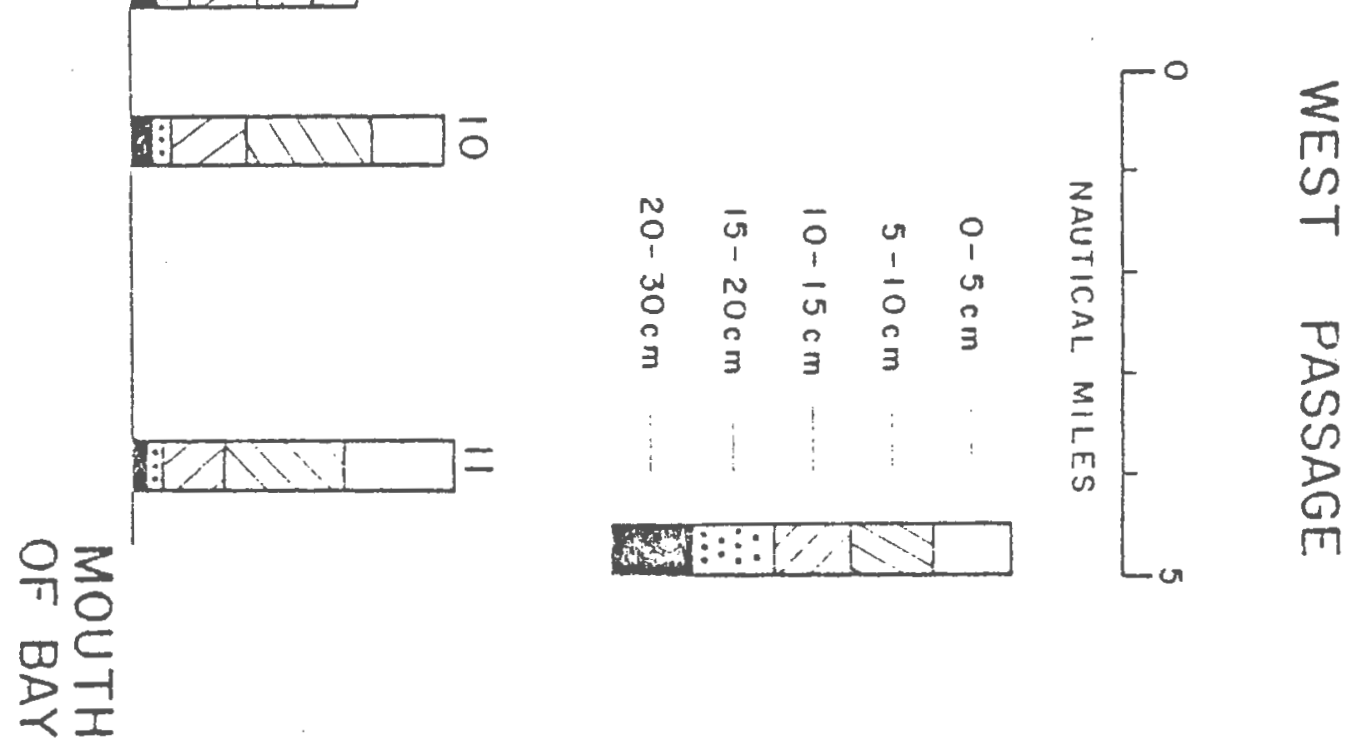


Figure 3. Hydrocarbon concentrations with depth in the sediments of the East Passage vs distance from the Providence River. 
TOTAL HYDROCARBON CONCENTRATION
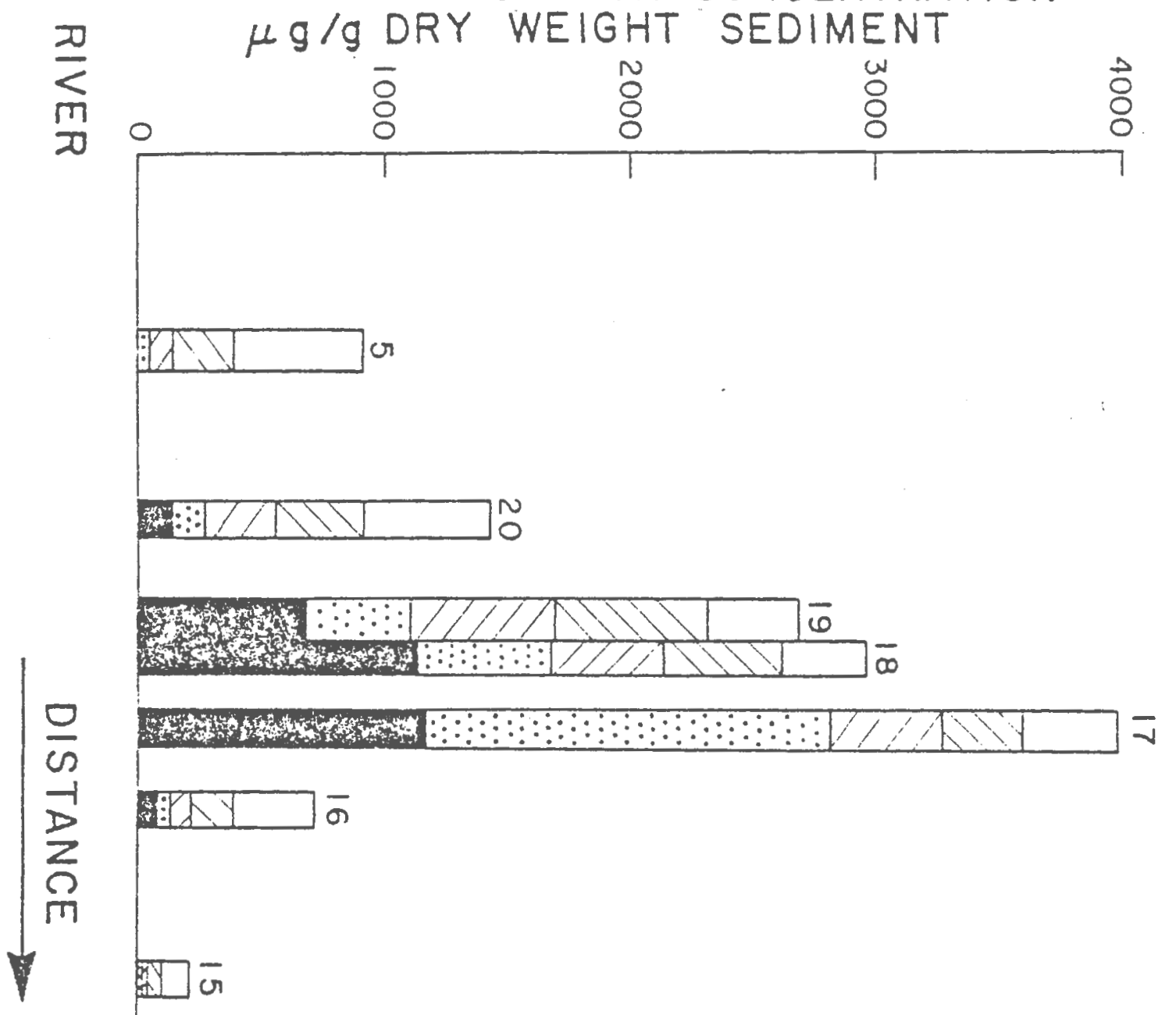

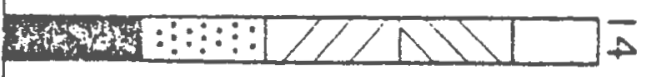

궁

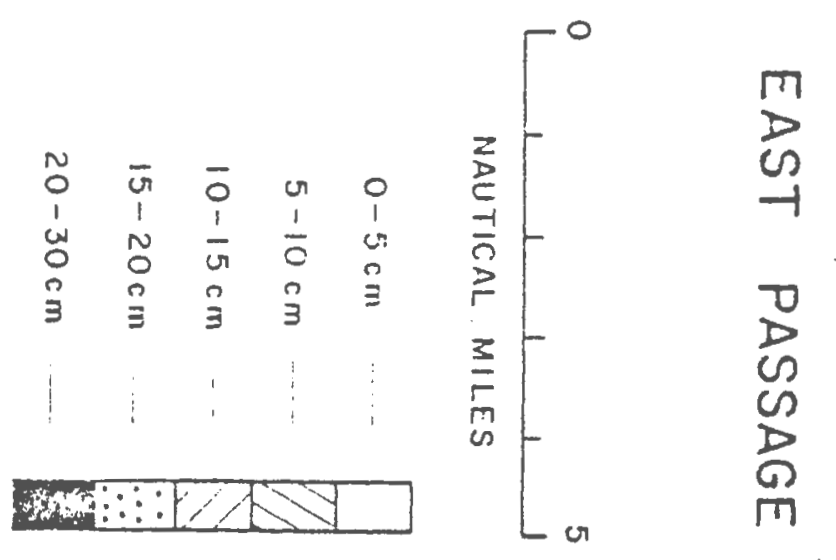

$\infty \subset$

거 
Table 1. Total hydrocarbon concentrations and percent resolved hydrocarbons with depth at stations $6,17,11$ and GB. 


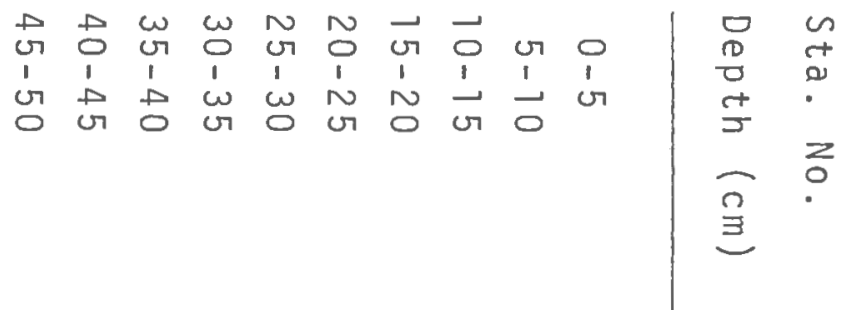

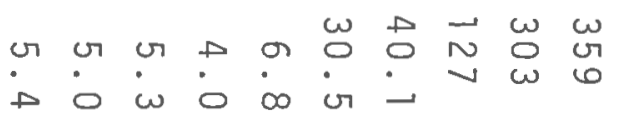

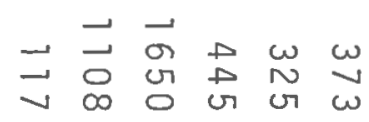

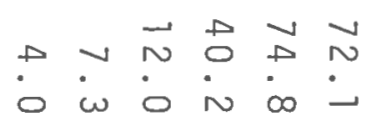

$$
\begin{aligned}
& \begin{array}{llllll}
\omega & \omega & D & \omega & D & D \\
\sim & \infty & 0 & V & G & G \\
& \sim & A & D
\end{array}
\end{aligned}
$$

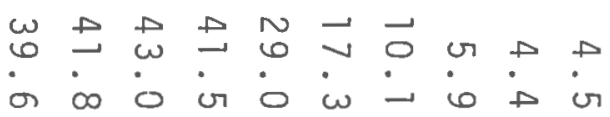

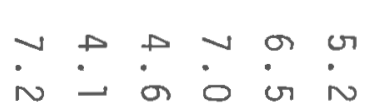

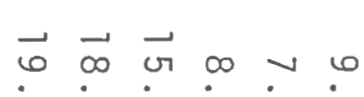

$$
\begin{aligned}
& \text { w ir or } v \text { or in }
\end{aligned}
$$

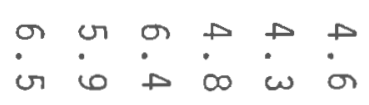

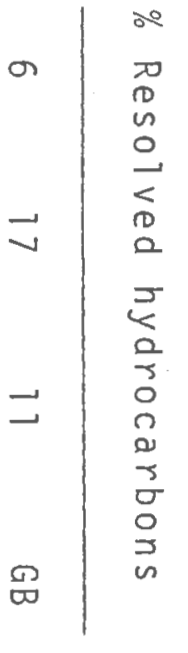


unusually high values found at 15-20 and 20-25 cm. Station 11 (lower West Passage) represents a relatively unpolluted core to use as a comparison with other more contaminated sediments. The Greenwich Bay station (GB) was included to illustrate values found for a depositional area somewhat removed from the direct effects of sewage effluent and other hydrocarbon sources from the Providence River. Greenwich Bay has input from sewage effluent (R.I. Department of Health, 1975), boating, and is of further interest in the controversy over shellfishing areas which will be discussed at greater length in the discussion section. Stations 6 and 11 show a decrease in concentration of total hydrocarbons with depth in the core; whereas, Station 17 has a substantial increase with depth to $15-20 \mathrm{~cm}$ and then a decrease to $30 \mathrm{~cm}$. Station GB shows a decreasing trend, but not as pronounced as samples 6 and 11 . The percent resolved hydrocarbons are helpful in detecting compositional changes in the sediment samples progressing down the Bay and with depth in the cores (Table 1). This value generally increases going away from the Providence River and downcore at each station (Stations 6 and 11). A similar trend was found by Van Vleet and Quinn $(1977,1978)$. Also, GB values for percent resolved hydrocarbons increase with depth in the core, but at a slower rate than stations 6 and 11 . In contrast to this trend of increasing percent resolved hydrocarbons with depth in the core, there are minimum values for station 17 at $15-20 \mathrm{~cm}$ and $20-25 \mathrm{~cm}$ which correspond to the maximum hydrocarbon values found in this core.

Table 2 presents data on the major biogenic hydrocarbon $\left(\mathrm{HC}_{344}\right.$, molecular weight 344) which has also been observed in other sediment samples from Narragansett Bay and Rhode Isiand Sound (Farrington and 
Table 2. Concentrations of $\mathrm{HC}_{344}$, organic carbon, and percentage of organic carbon as total hydrocarbon with depth at stations $6,17,11$ and GB. 


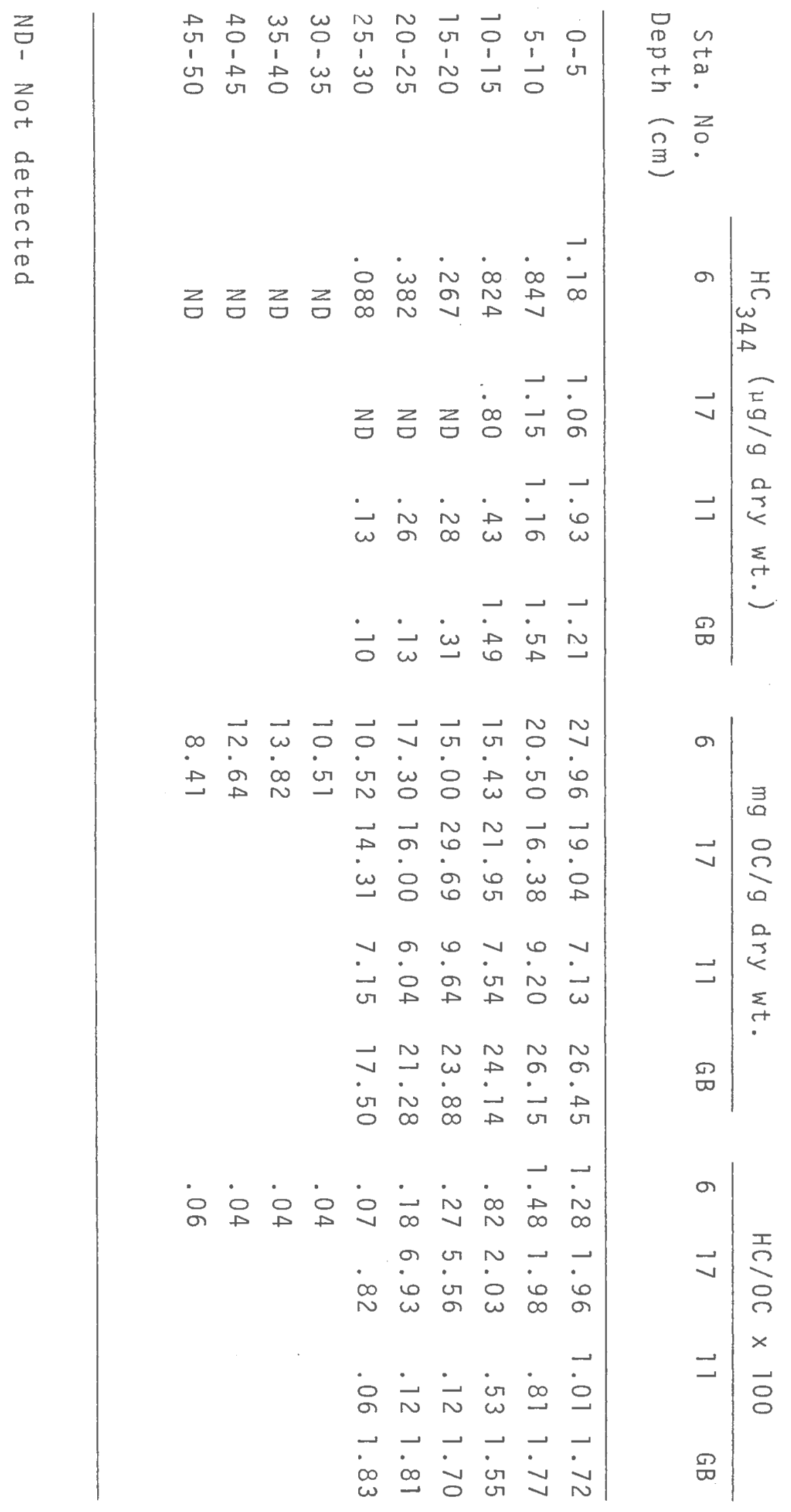


Quinn, 1973a; Boehm and Quinn, 1978; Van Vleet and Quinn, 1978). Stations 6,17 , and 11 have a trend of decreasing $\mathrm{HC}_{344}$ concentration with depth in the core. The GB station also has a general decrease in $\mathrm{HC}_{344}$ concentration, but there is a slight increase in two sections of the core, $5-10 \mathrm{~cm}$ and $10-15 \mathrm{~cm}$. Furthermore, the concentration in surface samples $(0-5 \mathrm{~cm})$ for all 20 stations varied from $0.2-3.5 \mu \mathrm{g} / \mathrm{g}$ dry wt sediment, and as much as $5.6 \mu \mathrm{g} / \mathrm{g}$ in a deeper section $(15-20 \mathrm{~cm})$ of an East Passage core (Station 18). The range of values for the surface sediments are similar to those found by the above authors. Also included in Table 2 are the $\mathrm{mg}$ organic carbon $(O C) / g$ dry wt sediment and percentage of $O C$ as $H C(H C / O C \times 100)$. These are included to illustrate the variations found for different environments in the Bay. Stations 6 and $G B$ follow a trend of decreasing concentration of $\mathrm{OC} / \mathrm{g}$ with depth in the core while station 17 shows a general increase with depth through $20 \mathrm{~cm}$ and then a decrease. The latter value corresponds to the same depth at which there is a maximum total hydrocarbon concentration $(15-20 \mathrm{~cm})$. On the other hand, station 11 values remain relatively constant through the top $30 \mathrm{~cm}$. Stations 5 and 11 show a decrease in the percentage of $O C$ as $H C$ with depth in the core while $G B$ values remain relatively constant with depth. Again, station 17 values for $\mathrm{HC} / \mathrm{OC} \times 100$ generally increase with depth through the top $25 \mathrm{~cm}$ and then drop off in the last section of the core $(25-30 \mathrm{~cm})$.

Figure 4 illustrates that the total HC/OC percent in surface sediments $(0-5 \mathrm{~cm})$ decreases with distance from the River. These values are in good agreement with those from the Providence River, midNarragansett Bay, and Rhode Island Sound (Farrington and Quinn, 1973a; Van Vleet and Quinn, 1977, 1978; Boehm and Quinn, 1978). For the West 
Figure 4. Percentage of organic carbon as total hydrocarbon in the East and West Passages with distance from the Providence River to the mouth of Narragansett Bay (surface sediments, $0-5 \mathrm{~cm}$ ). 

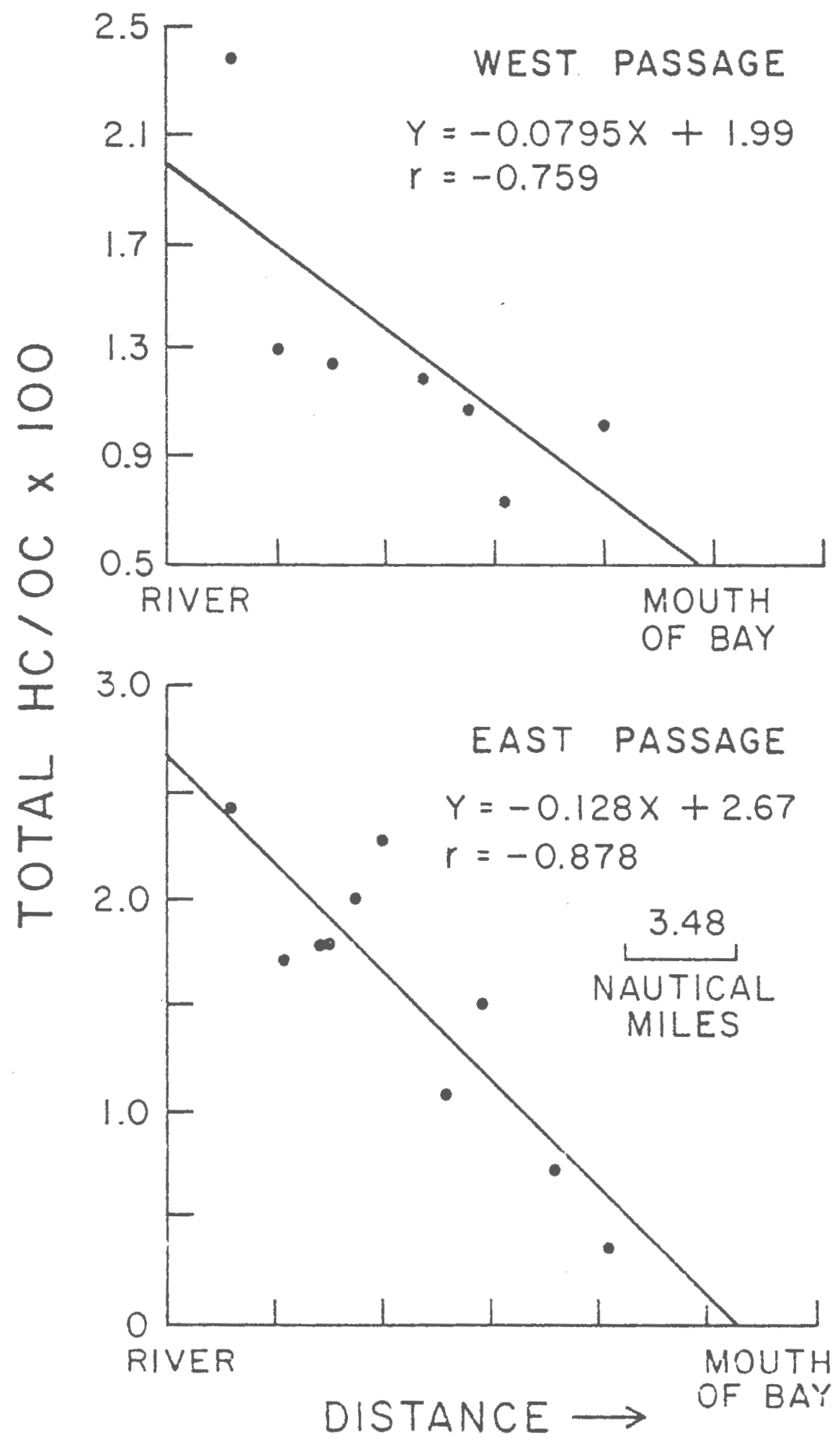
Passage, the values had a correlation coefficient of -0.759 while the corresponding value in the East Passage was -0.878 . Both correlation coefficients were significant at the $95 \%$ confidence level. The results are different for $\mathrm{HC}_{344} / \mathrm{OC} \times 100$ in surface sediments $(0-5 \mathrm{~cm})$ vs distance from the Providence River (Figure 5). In the West Passage, the values increase with distance from the River with a correlation coefficient of 0.817 which is significant at the $95 \%$ confidence level. In contrast, the East Passage values do not follow such a clearcut. trend. The correlation coefficient is 0.227 and is not significant at the $95 \%$ confidence level. As mentioned previously, the East Passage samples do not fit the expected trend, and hypotheses for these anomalies are addressed in the discussion section.

Figure 6 illustrates the relationship of $\mathrm{HC}_{344}$ vs $\mathrm{OC}$. This is a combination of the surface samples $(0-5 \mathrm{~cm})$ for the East and West Passages. The correlation coefficient was 0.415 , and was not significant at the $95 \%$ confidence level. The West and East Passages examined separately had correlation coefficients of 0.523 and 0.332 respectively, and were also not significant at the $95 \%$ confidence level. In contrast, Boehm and Quinn (1978) found a high correlation (0.955) between $\mathrm{HC}_{344}$ and organic carbon in Rhode Island Sound sediments. Figure 7 illustrates the relationship between total hydrocarbon values and organic carbon for surface sediments $(0-5 \mathrm{~cm})$. The correlations are high for both the West and East Passages ( 0.878 and 0.920 ) and are significant at the $95 \%$ confidence leve1. These results are similar to those of Boehm and Quinn (1978) for. Rhode Island Sound sediments (correlation coefficient of 0.855$)$.

Packed column gas chromatograms of hydrocarbons from station 6 
Figure 5. Percentage of organic carbon as $\mathrm{HC}_{344}$ in the East and West Passages with distance from the Providence River to the mouth of Narragansett Bay (surface sediment, 0-5 cm). 


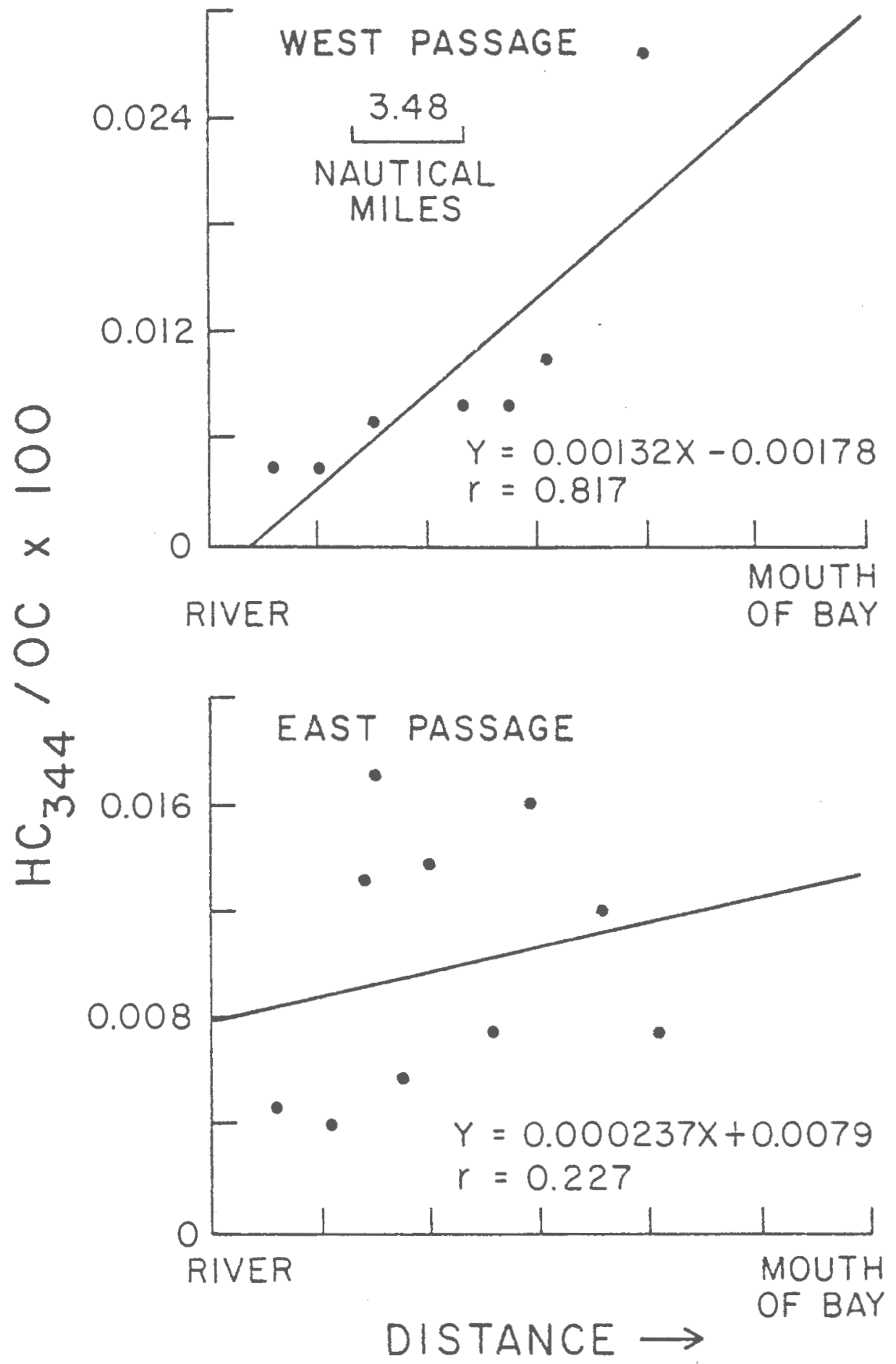


Figure 6. Relationship of $\mathrm{HC}_{344}$ to organic carbon in surface sediments $(0-5 \mathrm{~cm})$ of Narragansett Bay. 


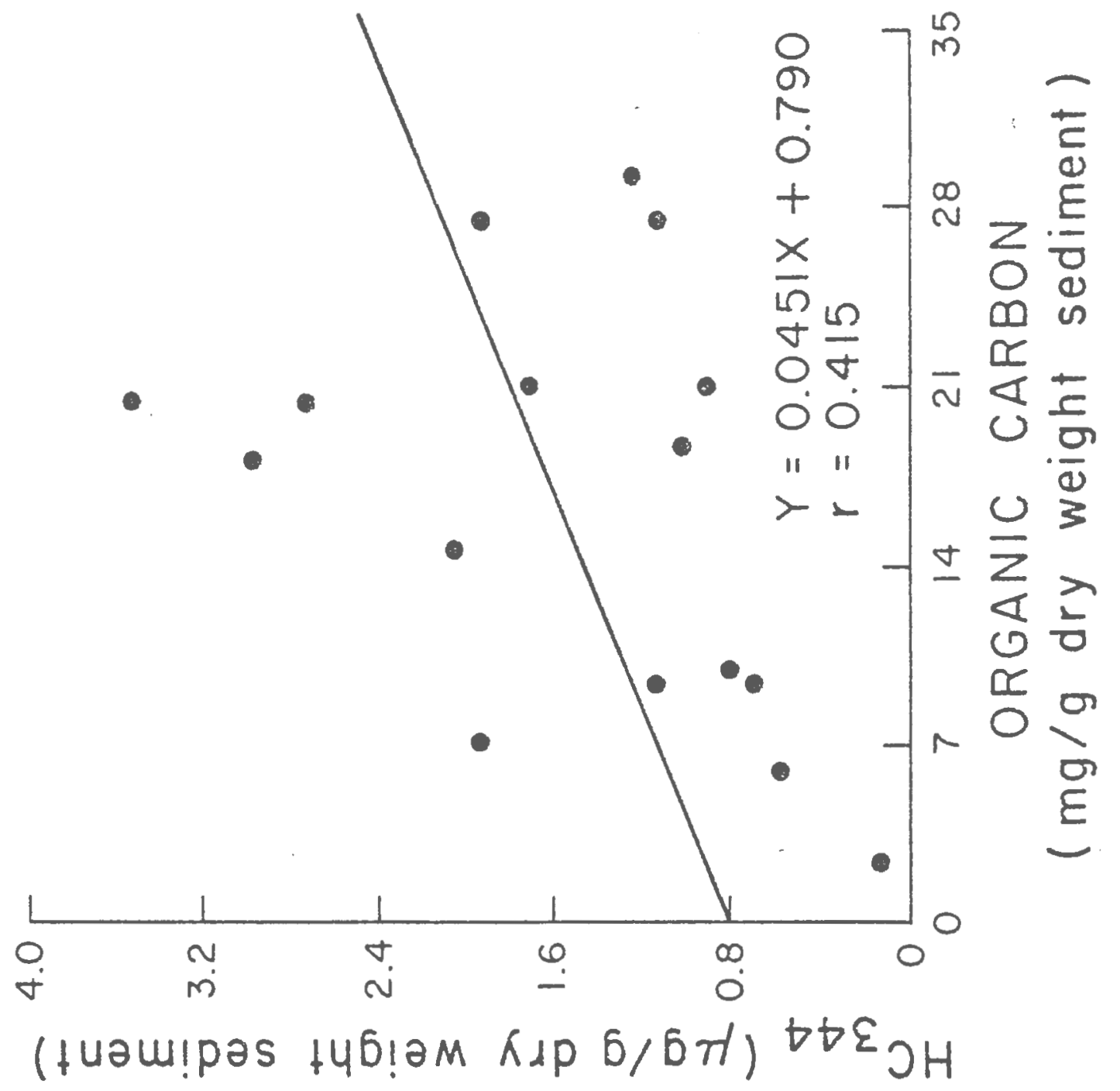


Figure 7. Relationship of total hydrocarbon content of sediments in East and West Passages to its organic carbon content. 

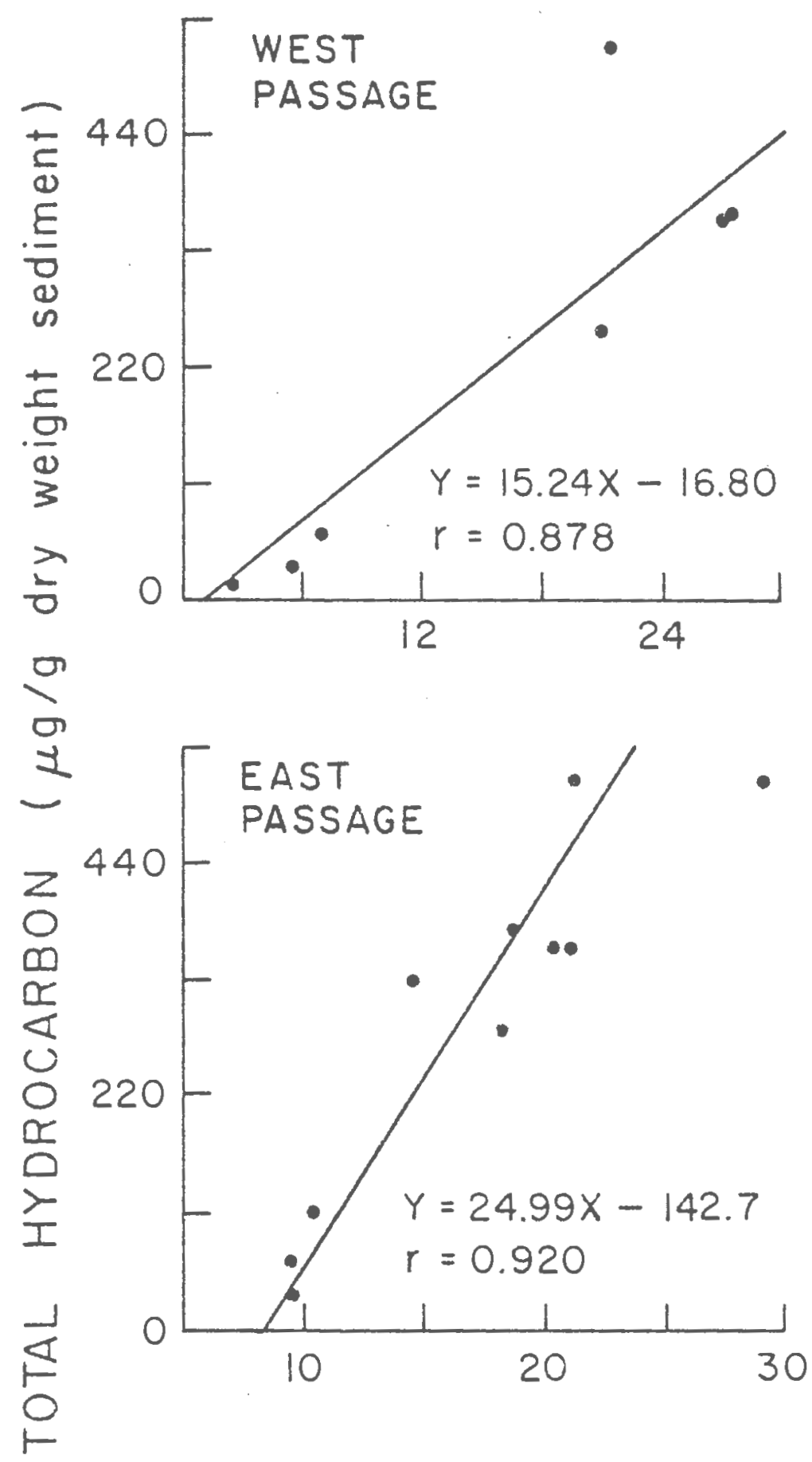

ORGANIC CARBON

( $\mathrm{mg} / \mathrm{g}$ dry weight sediment) 
(Figure 8) are useful in the discussion of various parameters: the increasing predominance of odd-chain $n$-alkane peaks $\left(n C_{25,27,29,31}\right)$ with increasing depth in the core in relation to the decrease of unresolved complex mixture (UCM - comprised of cycloalkanes, aromatic and naphtheno-aromatic hydrocarbons), and increasing emergence of $\mathrm{HC}_{344}$, pristane, and $\mathrm{C}_{17}$ with depth in the core.

Finally, Figure 9 shows glass capillary gas chromatograms of the PENNANT oil from the Liberian tanker PENNANT which ran aground off Popasquash Point (between stations 19 and 20) in the East Passage on 4/9/73 and spilled 250,000 gallons of \#6 fuel oil (Hyland, 1977). Also shown is a chromatogram from a section $(15-20 \mathrm{~cm})$ of station 17 from the " East Passage which had the highest concentration of hydrocarbons in any of the cores. An attempt was made to match the hydrocarbons in this section of the core with the oil sample using glass capillary gas chromatography. The match was not a good one (correlation 0.29, personal communication, Dr. Eva Hoffman), and the rationale for dismissing the PENNANT oil as the source of the high. hydrocarbon values found in the East Passage is elaborated on in the discussion section. 
Figure 8. Gas chromatograms (10\% SP-1000, packed columns) of hydrocarbons in sediment core from station 6 . Operating conditions given in Materials and Methods section.

Note: $20=$ internal standard $\mathrm{nC}_{20}$ $25-31=n-a 7$ kanes of that carbon number $X=$ cycloalkene $\mathrm{HC}_{344}(\mathrm{MN}=344)$ UCN = unresolved complex mixture of hydrocarbons $P R=$ pristane 


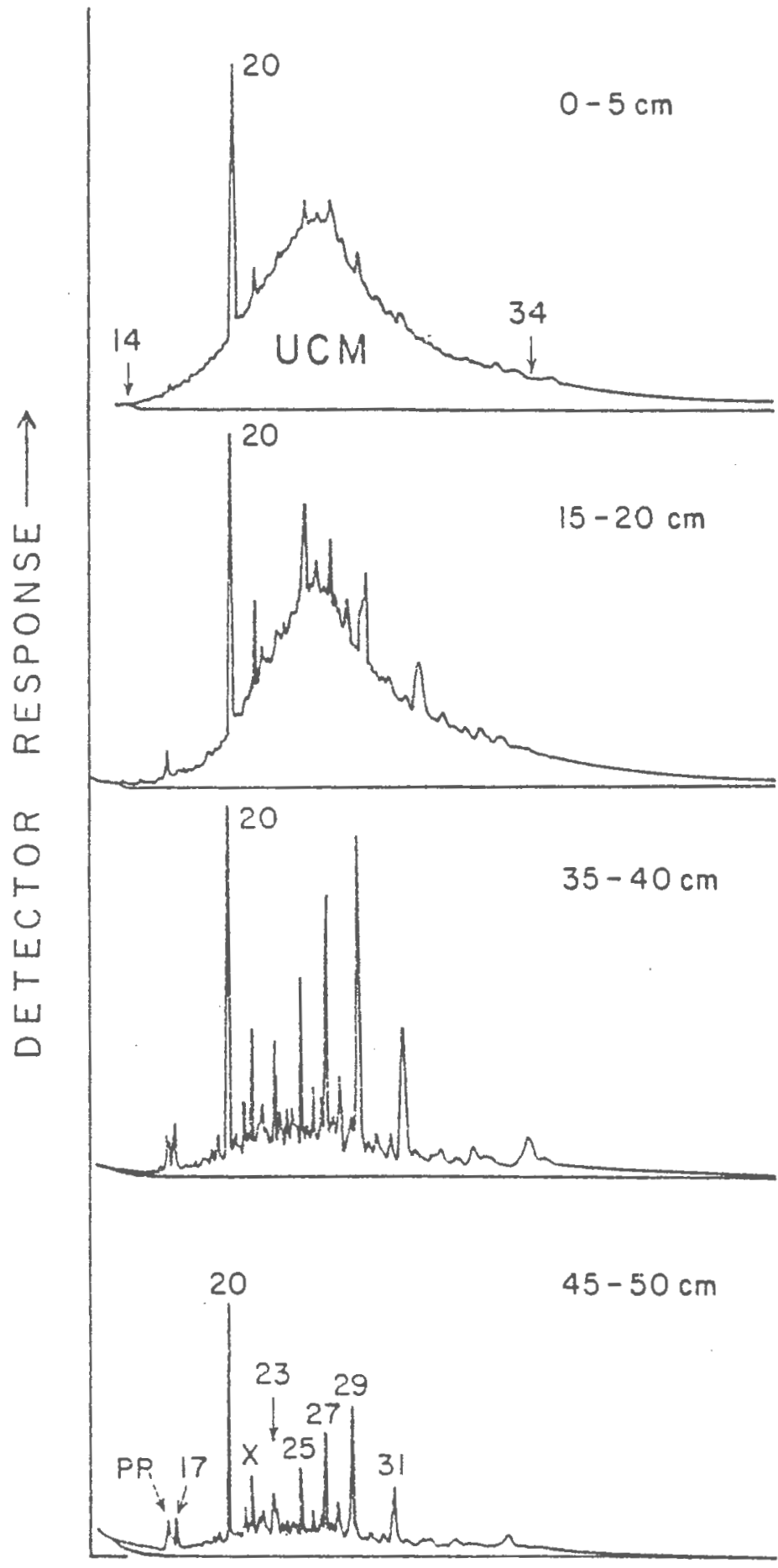

INCREASING TIME AND TEMPERATURE $\rightarrow$ 
Figure 9. Gas chromatogram (OV-101, capillary column) of hydrocarbons in PENNANT oit sample (a) and in sediment core 17, 15-20 cm (b). Operating conditions given in Materials and Methods section. Note: 20 = internal standard $\mathrm{nC}_{20}$ (b only).

$17,18,20=n$-alkanes of that carbon number

UCM = unresolved complex mixture of hydrocarbons

Phy = phytane

$P R=$ pristane 


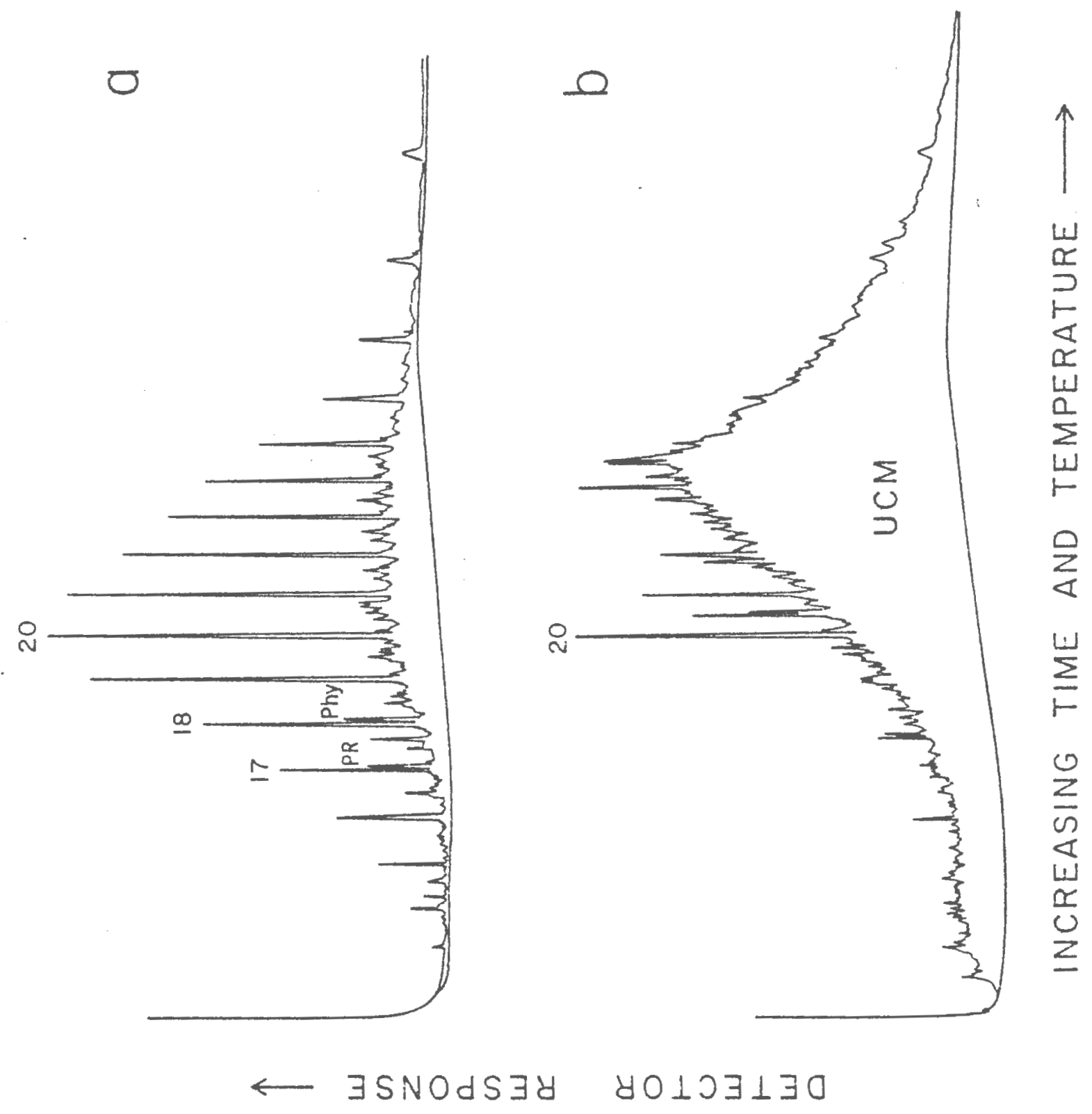




\section{Discussion}

From data obtained at stations 1-4 and the Fields Point sewage treatment plant (Figure 1), Van Vleet and Quinn (1977) estimated that sewage effluent can account for $42-84 \%$ of the total suspended hydrocarbons in the Providence River. They also estimated that approximately $50 \%$ of the suspended hydrocarbons are deposited in the River sediments and the remaining $50 \%$ are flushed out into Narragansett Bay. Based on this information, one would expect a decrease in surface sediment hydrocarbon concentration with distance from the Providence River. Schultz and Quinn (1977) found that the hydrocarbon composition and concentration of suspended material is fairly close to that of the sediment (Farrington and Quinn, 1973a) from the same station. Both suspended and sedimentary hydrocarbons decrease in concentration from the Providence River stations to the mid and lower Bay areas. Furthermore, the predicted hydrocarbon concentrations in suspended material from Narragansett Bay, using the hydrodynamic model of Kremer and Nixon (1978), and the observed hydrocarbon concentrations were in excellent agreement. This suggests that the major source of suspended hydrocarbon input into Narragnasett Bay is from the Providence River. Also, the model indicates that sedimentation as well as dilution are important processes in lowering the suspended hydrocarbon concentrations in the Bay.

Morton (1967) examined the spatial and temporal trends of suspended sediment in Narragansett Bay and Rhode Island Sound and concluded in past: 1) bottom currents flowing into theBay carry a significant amount of suspended material into the estuary, and 2) only a small amount of 
suspended matter derived from fluvial sources is transported through the Bay to the ocean. A1so, surveys of West and East Passages show a fourfold decrease in turbidity from the head of the Providence River to the mouth of the Bay (Schenk and Davis, 1973). Collins (1976) found that near-bottom turbidity is least in the East, and that concentrations of near-surface suspended material in the West Passage decrease from north to south while near-bottom concentrations increase from north to south. However, in the East Passage both near-surface and near-bottom suspended material concentrations generally diminish seaward. Furthermore, coarse silt size near-bottom material, predominant in lower East and West Passages, increased in amount toward the middle of West Passage and decreased toward the middle of the East Passage. Schultz and Quinn (1973) found that the ebb tide introduces suspended matter from marshes to the west side of the West Passage and this may explain the increase in coarse silt particles toward middle West Passage. In contrast to the West Passage, the East Passage with little marsh area showed a northward decrease in near-bottom coarse silt caused by deposition during landward flow (Collins, 1976). This could be a possible explanation for the fairly dramatic drop in the hydrocarbon concentration between stations 8 and 9 in the West Passage (Figure 2). Station 9 is opposite marsh areas in the western part of the West Passage while station 8 is opposite Wickford Cove (south of $Q$ in Figure 1) which has many boats, etc., and is near the former Navy base at QuonsetDavisville. It is possible that lickford Cove could be a current source of hydrocarbons via the boating activity, and that the QuonsetDavisville complex was a source in the past.

The core samples were collected to represent various depositional 
environments in Narragansett Bay, and also provide a more extensive survey of hydrocarbons in Bay sediments than previously done. McMaster (1960) found that fine detritus, clayey silt and sand-siltclay are the most abundant types of sediment on the bottom surface. The sediment load available for deposition is small and is composed of fine and very fine sand, silt, and clay. During present environmental conditions (approximately the past 100 years), fine sediments, clayey silt and sand-silt-clay have accumulated in the more protected middle and upper Bay. Moving down the Bay, there is a general change to coarser sediment textures which is probably related to tidal induced turbulence that reduces the amount of fine suspended sediment that can reach the bottom. The Bay circulation is generally dominated by tidal currents (Hicks, 1959), but wind also has a significant influence (Weisburg and Sturges, 1973). Both are important factors in terms of the distribution of pollutants throughout the Bay system. The general trend of decreasing hydrocarbons with distance from the Providence River would be expected given the type of sediment distribution found throughout the Bay. Hydrocarbons tend to be adsorbed better to finer siltyclay sediments than to the coarser sand-gravel type (Farrington and Quinn, 1973a; Meyers and Quinn, 1973).

The Army Corps of Engineers has also played a role in the physical alteration of Narragansett Bay (H.H. Gupti11, Army Corps of Engineers, personal communication). The Providence River has been dredged a number of times, most recently between 1967 and 1970 when a 40 foot deep channel was dredged and $6.3 \times 10^{6}$ cubic meters of material was taken to the Brenton Reef Dumping Ground approximately $5 \mathrm{~km}$ offshore Newport, Rhode Island (Boehm and Quinn, 1978). Until 1965 the Prudence Island Dumping Ground (southeast of Prudence Island) has been the receptacle 
for dredged material from Sakonnet Harbor, Pawtuxet Cove, Warwick Cove, and Wickford Cove. Other operations included rock removal from the Warren River in 1887, channel and anchorage clearing in 1959 to be used as fill onshore at Bullocks Point Cove, and removal of rocks from the Providence River in 1973 which were dumped in a hole at the head of Narragnasett Bay. With the exception of samples taken in the vicinity of the Prudence Is Tand Dumping Ground, one would not expect sedimentary hydrocarbon values to be altered substantially by disposal of dredge spoils within Narragansett Bay proper. Station 14 (south of Prudence Island) may reflect the effects of the Prudence Island Dumping Ground. There is a slight increase in total hydrocarbon concentration with depth (Figure 3 ), and the values are considerably higher than in the West Passage at the same distance from the Providence River (Figure 2) and higher than those of stations 13 and 15. In addition, there have been a number of reported spills in the East Passage in the last 20 years (Fort Wetheri11 -W- 1960: Melville M- 1968: and Popasquash Point -between stations 19 and 20- 1973) which also could have contributed to the contamination seen at depth in the sediment of station 14, as well as other stations to be discussed later. Furthermore, not much is known about spills which occurred in the Bay much beyond 20 years ago, although there is a high probability that during World Wars I and II there were injections of $0 i 1$ into the Bay from defense operations.

Another area of interest is east of Prudence Island. Stations 17, 18, 19 show an increase in total hydrocarbon concentration with depth in the core (Figure 3). The maximum values occur at 15-20 cm and 20-25 cm. If one assumes a depositional rate near the mouth of the Providence 
River of about $1 \mathrm{~cm} /$ year for the top $15 \mathrm{~cm}$ of sediment (Goldberg et a1., 1977), and 1.5-2.0 mm/year for a site north of Conanicut Island (CFigure 1) as reported by Wade and Quinn (1978a), an estimate for the depositional rate for the area east of Prudence Island could be as high as $0.5 \mathrm{~cm} /$ year. Using this figure, the high hydrocarbon values found at 15-25 cm depth could have been deposited 30-50 years ago (1928-1948). Possible sources of this contamination were considered as follows: 1) There has been no report of dredging or dumping of dredged material in the area; 2) There was a spill of 250,000 gals of \#6 fuel oil in 1973 by the PENNANT off Popasquash Point in the East Passage. However, given the depth of burial, and the fact that the glass capillary chromatograms have a very low matching coefficient (0.29. Figure 9), it would seem that this spill was not the major source of the hydrocarbons seen at depth in stations 17, 18, 19: Other spills in the vicinity include 155 metric tons of \#2 fuel oil in Mount Hope Bay (January, 1969) and 22 metric tons of \# 6 fuel $0 i 1$ in January and March, 1970 in the East Passage near Melville (Farrington and Quinn, 1973a). However, these are relatively small amounts of petroleum and are too recent to be the major source of the contamination seen at depth in stations 17, 18, 19; 3) Bioturbation also was examined as a possible factor in the hydrocarbon distribution for these cores. Mcllaster (1967) showed compactness variability in both sands and muds in Narragansett Bay related to macrofaunal activity. Various polychaetes and shrimp species are known to alter the sediment structure in Narragansett Bay (Wayne Davis, personal communication). They can resuspend sediment and affect the fabric of the sediment by transporting material from one depth to another. Rhoads (1974) found that the influence of the macrofauna on the chemistry of the bottom would be 
limited to a depth of 10 to $30 \mathrm{~cm}$, depending on the species present. However, it is unlikely that the macrofauna could have such an extensive effect on the sediments at stations 17, 18, 19. One would expect a much more localized effect since a very dense population would be necessary to alter such a large area as that observed. Also, at a site north of Conanicut Island the mixing depth was estimated at only 2-3 cm (Wade and Quinn, 1978a); 4) As mentioned previously, sewage effluent does contribute a significant amount of hydrocarbons to the Narragansett Bay system. However, it is unlikely that this would be the source of the high hydrocarbon values at depth in the East Passage. For example, hydrocarbon values for stations 5 and 20 are lower than those for stations 17, 18, 19. Furthermore, there is not a depositional area at stations 17, 18, 19 which would concentrate hydrocarbons from sewage effluents from the Providence River; 5) The fuel depot at Melville (M - Figure 1), constructed in 1940, did have a pipe leakage in 1968 or 1969 that injected a Navy Special heavy fuel oil into the East Passage. Due to the time consideration, however, this is not a likely source of the oil seen at 15-25 cm depth. Also, information is not readily available concerning possible oil spills or tanker accidents as far back as World War II; 6) Other contributing factors could be pipeline breakages, contamination from the Taunton River which empties into Mount Hope Bay (Figure 1), or some spillage of oil due to the hurricane of 1938. Schultz and Quinn (1977) found that the total hydrocarbon concentration was low in the suspended material from the Taunton River in contrast to the high concentration found in the Providence River suspended material. Nevertheless, this information does not mean that in the past, the Taunton River-Mount Hope 
Bay area couldn't have been a significant source of the hydrocarbons seen at depth at stations 17, 18, 19. However, from the 1 imited information available, one can only speculate as to the source of the hydrocarbons at these stations.

An estimate of the total hydrocarbons surrounding stations 17 , 18, 19 would be informative as to the amount of oil contained in this area of the Bay. Using Kremer and Nixon's (1978) value for the area of the Bay as $23.118 \times 10^{7} \mathrm{~m}^{2}$, sectioning the Bay and measuring these: areas by planimetry one can estimate the area percent represented by the above three stations. Assuming $50 \%$ moisture for the sediment and a sediment density of $2.7 \mathrm{~g} / \mathrm{cm}^{3}$, one can determine the dry weight of sediment/volume. Furthermore, using a range of total hydrocarbon values for the $15-25 \mathrm{~cm}$ sections of the cores as $1000 \mu \mathrm{g} / \mathrm{g}-2800 \mathrm{\mu g} / \mathrm{g}$, one arrives at values of 2570 to 7180 metric tons total hydrocarbons $/ 10 \mathrm{~cm}$ in the areas of stations $17,18,19$.

Another useful calculation is the relative transport of hydrocarbons to the sediments of the Bay proper over the last 75 years. Van Vleet and Quinn (1977) estimated that 10,500 metric tons of riydrocarbons was the total input from the Providence River to the Bay during this time, and that approximately $50 \%$ of this was sedimented out in the River while 50\% was flushed out into the Bay. Using the percent area calculated by planimetry for each area of the Bay, the density of the sediment and the total hydrocarbon concentration for each $5 \mathrm{~cm}$ section, one car calculate the total hydrocarbon values for each area. Sumning these figures to $20 \mathrm{~cm}$ depth gives an approximation of the total nydrocarbon input to the Bay sediments during the 1ast 75 years: 22,600 metric tons. Therefore, the 51C0 metric tons hydrocarbons that have been flushed into the Bay proper over the past 75 years represent 
approximately $23 \%$ of the hydrocarbons found in the sediments of the Bay proper. This is reasonable when one considers the other possible sources of hydrocarbons: boating activities, spills, runoff, etc. Therefore, the above calculation further confirms that the Providence River is a significant source of hydrocarbons for Narragansett Bay.

This survey has illustrated the importance of sediment core analyses for hydrocarbons. If only the top $5 \mathrm{~cm}$ of the samples from the East Passage had been analyzed, the unusual trends found at depth would not have been seen, and the trends would have been similar to the West Passage. If at some later date that area was sampled after a spill, the results could be quite misleading. The issue that then arises is how deep in the sediment core must one go in such a survey. From the data obtained, it appears that there is a general levelling off point at about 20 to $25 \mathrm{~cm}$ or 25 to $30 \mathrm{~cm}$ depending on the area of the Bay. This depth probably coincides with the increased usage of petroleum hydrocarbons at the onset of the industrial revolution in North America at the end of the nineteenth century. Nevertheless, the unresolved complex mixture (UCM) does not disappear completely beyond this levelling off point as natural pyrolytic sources such as forest fires and urban air fallout from combustion of coal and wood can contribute to the unresolved hydrocarbons (Youngblood and Blumer, 1975; Farrington et a1., 1977; Van V1eet and Quinn, 1978).

Table 1 shows the trends for percent resolved hydrocarbons for stations $6,17,11, \mathrm{~GB}$. Core 6 reveals an increase in percent resolved with depth giving values ranging from approximately $5 \%$ to $29 \%$ for 25 to $30 \mathrm{~cm}$ and about $40 \%$ at 45 to $50 \mathrm{~cm}$. Stations 17 and $\mathrm{GB}$ maintain a fairly low and constant percent with evidence of hydrocarbon contam- 
ination down to $30 \mathrm{~cm}$. Unlike the latter stations, the percent resolved hydrocarbon values for station 17..increase with depth, but not to the extent observed at station 6 at 25-30 cm. Values for stations 6 and 11 are similar except at this depth. Furthermore, there is a general increase in percent resolved hydrocarbons in most surface sediments with distance from the Providence River and with depth in the core. Similar results were found by Van Vleet and Quinn (1977, 1978). Absolute values of resolved and unresolved hydrocarbons decrease with depth in the cores. However, the relative percent of the unresolved components decreases with depth. This is due to the decreased input of anthropogenic hydrocarbons and the emergence of the biogenic hydrocarbons $\left(C_{25}, C_{27}, C_{29}, C_{37}\right)$ with depth in the sediment. The latter are at the surface, but are not evident due to the high concentration of anthropogenic hydrocarbons. They can be seen more clearly in the surface of cores from "clean" areas (e.g. station 11, lower East Passage). Furthermore, the resolved components of the sedimentary anthropogenic hydrocarbons appear to be degraded much more rapidly than the natural plant wax hydrocarbons $\left(C_{25}, C_{27}, C_{29}, C_{37}\right)$. These hydrocarbons seem able to withstand microbial breakdown, via the residual plant matrix, as shown by their emergence in the lower sections of the cores; whereas, the anthropogenic hydrocarbons are adsorbed on the surface of the sediment particles and are therefore more susceptible to microbial and chemical degradation in the surface sediments (Thompson and Eglinton, 1978). There is a slight decrease in concentration of the biogenic n-alkanes until approximately $20-25 \mathrm{~cm}$ where the values remain fairly constant to 40-50 cm (station 6). Others (Boehm and Quinn, 1978; Farrington et a1., 1977; Wade and Quinn, 1978a) have found that the 
concentration of these biogenic hydrocarbons remain fairly constant throughout the sediment core down to $40-50 \mathrm{~cm}$.

Table 2 shows the trends for $\mathrm{HC}_{344}$ for stations $6,17,11, \mathrm{~GB}$. There was no apparent trend for the concentration in surface sediments from the mouth of the Providence River to the mouth of the Bay. However, there is a general trend of decreasing $\mathrm{HC}_{344}$ concentration with depth in these cores which is also typical of the other cores. $\mathrm{HC}_{344}$ and $\mathrm{HC}_{348}$, cycloalkenes with molecular weights 344 and 348 respectively, are found throughout Narragansett Bay and Rhode Island Sound. $\mathrm{HC}_{348}$ is lower in concentration than $\mathrm{HC}_{344}$ but still is measurable in the resolved components. Analyses of phytoplankton, zooplankton, particulate matter, and dissolved hydrocarbons do not reveal either of these compounds while the ocean quahog Arctica islandica and Mercenaria mercenaria do contain them (Boehm and Quinn, 1978). An experiment was done to determine if the fecal material of Mercenaria mercenaria was enriched in $\mathrm{HC}_{344}$ (Appendix 1). The results indicate that the fecal material is not a major source of $\mathrm{HC}_{344}$ in the sediments. Figure 8 shows chromatograms of 4 sections from station 6. It illustrates the above trends of the decrease in the UCM and the emergence of the odd chain hydrocarbons $C_{25}-C_{31}$ and $\mathrm{HC}_{344}$ with depth in the core.

Table 2 also illustrates trends for $\mathrm{mg} \mathrm{OC/g}$ dry weight sediment for stations $6,17,11, \mathrm{~GB}$. The $0 \mathrm{C}$ values follow the general trend of decreasing concentration in surface sediments with increasing distance from the Providence River as seen by other investigators (Farrington and Quinn, 1973a; Van Vleet and Quinn, 1977). There is also a general decrease in OC concentration with depth in the core at stations 6 and $\mathrm{GB}$ and constant values at 11. Exceptions to the decreasing concentration 
of $O C$ with depth in the sediment is seen in station 17 from the East Passage where the hydrocarbon levels are also unexpectedly high (Table 1). The high correlation of total hydrocarbons with $O C$ for surface sediments (Figure 7) was also seen by Boehm and Quinn(1978). The quantity of $O C$ in the sediment is due in part to the sedimentation rate and reactions in the sediment. Thus it appears that the relationship of $H C$ to $O C$ indicates that similar sedimentation factors are controlling the input of these materials into the sediment and reactions therein.

In addition to $\mathrm{OC}$, the $\mathrm{HC} / \mathrm{OC}$ percentage is another parameter which is helpful in tracking where hydrocarbons are transported in Narragansett Bay. Consideration of this value normalizes the fact that the sedimentation rate probably varies considerably due to physical factors and sediment types and controls the absolute hydrocarbon concentrations. This parameter is useful in comparing different stations, and hence different environments in the Bay. The general trend for the surface sedimentary $\mathrm{HC} / O \mathrm{C}$ percentage is decreasing values with increasing distance from the Providence River (Figure 4), and decreasing with depth in the core (Table 2). Values in the surface sediments range from approximately $6 \%$ in the upper Providence River (Farrington and Quinn, 1973a; Van V1eet and Quinn, 1977) to approximately 1\% in Rhode Island Sound (Boehm and Quinn, 1978). The results from this study indicate that in the West Passage the values are $1.28 \%$ (station 6) to approximately $1 \%$ in the lower Bay (station 11); while in the East Passage the values are $1.73 \%$ (station 20 ) and drop to $0.35 \%$ (station 12) in the lower Bay. Moving down the Bay, silty material is lower in hydrocarbons relative to $O C$ due to inputs of $O C$ from other sources 
which contain a smaller percentage of hydrocarbons compared to the Providence River inputs. Also, some of the hydrocarbons have probably been degraded by microbial action due to a longer residence time in the water column, and greater surface area per unit weight. Hence, there is a general decrease in values of the $\mathrm{HC} / O \mathrm{C}$ percentage with distance from the Providence River where the hydrocarbon; inputs are high. An important note is that in areas of high hydrocarbon content (e.g. GB and station 17) at depth in the core, the $H C / O C$ percentages are higher than would normally be expected. For example, the two highest values found in Narragansett Bay proper were at station 17 at $15-20 \mathrm{~cm}$ and $20-25 \mathrm{~cm}$ with $\mathrm{HC} / \mathrm{OC}$ percentages of $5.56 \%$ and $6.93 \%$ respectively (Table 2). These values are in the same range as those for the Providence River (Farrington and Quinn, 1973a; Van Vleet and Quinn, 1977). Furthermore, at these depths $(15-20 \mathrm{~cm})$ the total hydrocarbon (Table 1) and $O C$ values (Table 2) were also unusually high.

The ratio of $\mathrm{HC}_{344}$ to $\mathrm{OC}$ in surface sediments increased with distance from the Providence River and was highly correlated in the West Passage; whereas, there was no obvious trend in the East Passage (Figure 5). This trend is probably due to the increase in input of biogenic material including $\mathrm{HC}_{344}$ which is higher relative to the input of organic carbon as one goes down the Bay, and to the unusual accumulation of hydrocarbons, whose possible sources were given previously, in the East Passage samples. Furthermore, there was poor correlation between $\mathrm{HC}_{344}$ and $\mathrm{OC}$ (Figure 6) which was different from the results of Boehm and Quinn (1978) in Rhode Island Sound sediments. There are more anthropogenic hydrocarbons in the Bay than in Rhode Island Sound which would increase the $O C$ value for the Bay over that for 
the Sound. Also the Bay has a different input of $O C$ than Rhode Island Sound, including petroleum, which does not include $\mathrm{HC}_{344}$, or compounds which are converted to $\mathrm{HC}_{344}$. These factors contribute to the difference between the correlations of $\mathrm{HC}_{344}$ and $\mathrm{OC}$ for Rhode Island Sound and Narragansett Bay sediments.

\section{CONCLUSIONS}

From this investigation and previous studies done on sedimentary hydrocarbons in Narragansett Bay, it is evident that sewage effluents do have a measurable input to the Bay system. This discharge not only enters the sediments, but also is taken up by clams. Sewage effluent is the major cause for the closing of shellfishing areas in the Providence River and the northern Bay. Depuration of clams is done mainly to eliminate coliform bacteria, and does not take into account other contaminants such as metals, petroleum hydrocarbons, or chlorinated hydrocarbons which could be potentially hazardous. There is some controversy as to whether or not the clams, under chronic pollution conditions, are able to rid themselves of these petroleum hydrocarbons adequately. However, available evidence (Boehm and Quinn, 1977 ) suggests that the process would probably require at least one year, if in fact, the hydrocarbons were available for outward mass transfer. Shellfishing is a viable industry in Rhode Island, and the closing of these shellfishing areas constitutes an economic loss for the state.

The Fields Point treatment plant, the major single composite source of hydrocarbons in the Providence River and Narragansett Bay, dischárges hydrocarbons that resemble \#2 fuel 011 , \#6 fuel oil, and 
used crankcase oil. These oils probably reach the sewage system via accidental and/or intentional discharges of used crankcase Tubricating oils, and atmospheric deposition of hydrocarbons and subsequent washing of these hydrocarbons and oils from the roads into the sewage systems. It has been estimated (NeTson, 1978) that crankcase drainings may constitute $38.1 \%$ of all $0 i 1$ pollution of the environment. Furthermore, according to Porricelli et al. (1971), up to $30 \%$ of the total petroleum input to the ocean may be from waste motor oil. Therefore, a substantial amount of the estimated 226 metric tons/year input of hydrocarbons from the Fields Point sewage treatment plant could be from crankcase oil. One way to reduce this source of hydrocarbons would be to set up an oil recycling program. In the past, this has not been economically feasible. However, a recent article (Ne1son, 1978) indicated that the economics have improved. Tackling the problem closer to its source is more reasonable than making costly adjustments to sewage treatment plants, storm and sanitary sewers, or elaborate schemes for clam depuration that may not eliminate the contaminants satisfactorily anyway. The oil recycling approach would solve the problems of a substantial amount of the oil pollution of the Bay and shellfish contamination while at the same time recycling a valuable, nonrenewable resource at a profit. 


\section{ACKNOWLEDGEMENTS}

We would like to express our appreciation to the following individuals who contributed to this research: Stan Spink, the skipper of BILLIE II, and John Sisson, the skipper of the DULCINEA, for sample collection; the Environmental Protection Agency (Narragansett, Rhode Island) for use of their gravity corer; Jan Johnson, Gary Mills, and Terry Wade for their help in collecting sediment samples: Dick Sisson (Department of Natural Resources, Rhode Island) for collecting Mercenaria mercenaria from Narragansett Bay; Gary Mills and Terry. Wade for patient instruction on organic carbon and hydrocarbon analysis techniques respectively; and Eva Hoffman for glass capillary analyses.

This study was supported by a research grant (04715844088) from the National Sea Grant Program. 


\section{REFERENCES}

API, EPA, USCG. 1971. Proceedings of the Joint Conference on Prevention and Control of $0 i 1$ Spills. Washington, D.C., $544 \mathrm{pp}$.

API, EPA, USCG. 1973. Proceedings of the Joint Conference on Prevention and Control of $0 i 1$ Spills. Washington, D.C.,834pp. API, EPA, USCG. 1975. Proceedings of the Joint Conference on Prevention and Control of 0 il Spills. San Francisco, Calif., $612 \mathrm{pp}$.

Blumer, M. 1970. 0il pollution of the ocean. WHOI Instit. Rep. No. 70-46. In $0 i 7$ on the Sea, Proceedings of a Symposium on Scientific and Engineering Aspects of $0 i 1$ Pollution of the Sea, David P. Hoult (ed.), New York Plenum Press, 5-13.

Blumer, M., Blukker, P.C., Cave11, E.B., Duckworth, D.F. 1972.

Petroleum, In $\underline{A}$ Guide to Marine Pollution, E.D. Goldberg (ed.), Gordon and Breach Sci. Publ., New York, 19-40.

Blumer, M., Guillard, R.R.L.,Chase, T. 1971. Hydrocarbons of marine phytoplankton. Marine Biology 8, 183-189.

Blumer, M., Sass, J. 1972. The W. Falmouth $0 i 1$ Spi11, II. Chemistry, WHOI Technical Rep. No. 72-19, 60pp.

Boehm, P.D., Quinn, J.G. 1977. The persistence of chronical1y accumulated hydrocarbons in the hard shell clam Mercenaria mercenaria. Marine Biology 44, 227-233. Boehm, P.D., Quinn, J.G. 1978. Benthic hydrocarbons of Rhode Island Sound. Est. Coastal Mar. Sci. 6, 471-494. 
Burns, K.A., Teal, J.H. 1973. Hydrocarbons in the pelagic Sargassum community. Deep-Sea Res. 20, 207-211.

46 Collins, B.P. 1976. Suspended material transport: Narragansett Bay 28 area, Rhode Island. Est. Coastal Mar. Sci. 4, 33-44.

Ducsik, D.W. (ed.) 1971. Power, Pollution, and Public Policy. MIT Press, Cambridge, Mass., 243pp.

Eglinton, G., Maxwel1, J.R., Philp, R.P. 1975. Organic Geochemistry of sediments from contemporary aquatic environments, In Advances in Organic Geochemistry 1973, B. Tissot and F. Brenner (eds.), Proceedings 6th International Meeting, Editions Technip, Paris, 941-961.

Evans, D.R., Rice, S.D. 1974. The effects of 011 on marine ecosystems. Fisheries Bulletin 72, 625-638.

Farrington, J.W. 1971. Benthic Lipids of Narragansett Bay - Fatty Acids and Hydrocarbons. Ph.D. Thesis, Univ. of R.I., $141 \mathrm{pp}$. ecit Farrington, J.W., Frew, N.M., Gschwend, P.M., Tripp, B.W. 1977. 288 Hydrocarbons in cores of Northwestern Atlantic coastal and continental margin sediments. Est. Coastal Mar. Sci. ㅁ, 793-808. X $<D 172$ Farrington, J.W., Meyers, P.A. 1975. Hydrocarbons in the marine Esis

environment, In Environmental Chemistry, Vol.1, G. Egl inton (ed.),

The Chemical Society, Burlington House, London, Chapter 5,109-137.

Farrington, J.h., Quinn, J.G. 1973a. Petroleum hydrocarbons in Narragansett Bay: I. Survey of hydrocarbons in sediments and clams (Mercenaria mercenaria). Est. Coastal Mar. Sci. I, 71-79. 
Q:Sis Farrington, J.W., Quinn, J.G. 1973b. Biogeochemistry of fatty acids 6425

in recent sediments of Narragansett Bay, R.I. Geochim. Cosmochim. Acta 37, 259-268.

Farrington, J.W., Quinn, J.G. 1973c. Petroleum hydrocarbons and fatty acids in wastewater effluents. $\underline{J}$. Water Pollut. Control Fed. 45, 704-712.

Farrington, J.W., Tea1, J.M., Parker, P.L. 1975. Petroleum Hydrocarbons. Chap. 1 In Strategies for Mar. Pollut. Monitoring, E.D. Goldberg (ed.), John Wiley \& Sons, Inc., 3-34.

Franklin, G., Brown, C. 1977. Hydrocarbons in Quonset-Davisville. In The Redevelopment of Quonset-Davisville: An Environmental Assessment. Marine Technical Report No. 55, Coastal Resources Center, Univ. of R.I., 200pp.

Giger, W., Reinhard, M., Schaffner, C., Stumm, W. 1974. Petroleum derived and indigenous hydrocarbons in recent sediments of Lake Zug, Switzerland. Environ. Sci. Technol. 8, 454-455.

Goldberg, E.D., Gamble, E., Griffin, J.J., Koide, 11. 1977. Pollution history of Narragansett Bay as recorded in its sediments.

Est. Coastal Mar. Sci. $\underline{5}, 549-561$.

GCl Hardy, R., Mackie, P.R., Whittle, K.J. 1977. Hydrocarbons and I66 petroleum in the marine ecosystem- a review. Rapp. $\underline{P} . \underline{V}$. Reun. int. Explor. Mer. 171, 17-26.

Hicks, S.D. 1959. The physical oceanography of Narragansett Bay. Limnol. Oceanogr. 4, 316-327. Hoffman, E.J., Quinn, J.G. 1978 (in press). A comparison of ARG0 MERCHANT oil and sediment hydrocarbons from Nantucket Shoals. In Proceedings of the ARGO MERCHANT Symposium, Univ. of R.I. 
Hotte1, H.C., Howard, J.B. 1971.' New Energy Technology - Some Facts and Assessments. MIT, Cambridge, Mass., 364pp. Hyland, J.L. 1977. A review of 011 polluting incidents in and around New England. Environmental Protection Agency Ecological Research Series. 34pp.

Kremer, J.N., Nixon, S.W. 1978. A Coastal Marine Ecosystem: Simulation and Analysis. Ecological Studies 24, Springer-Verlag, New York,217pp. Mcllaster, R.L. 1960. Sediments of Narragansett Bay system and Rhode Island Sound, Rhode Island. J. of Sedimentary Petrology 30 , 249-274.

Mclaster, R.L. 1967. In Estuaries, edited by G.H. Lauff, Am. Assoc. Adv. Sci., Washington, D.C.,Pub7. No. 83, 261-267.

Menze1, D.W., Vaccaro, R.F. 1964. The measurement of dissolved organic and particulate carbon in seawater. Contribution No. 1427 WHOI, $138-142$.

Meyers, P.A., Quinn, J.G. 1973. Association of hydrocarbons and mineral particles in saline solution. Nature 244, 23-24. Mi11s, G.L., Quinn, J.G. 1978. Determination of organic carbon in marine sediments by persulfate oxidation. Submitted to Chemical Geology.

Morton, R.W. 1967. Spatial and temporal observations of suspended sediment: Narragansett Bay and Rhode Island Sound. Naval Underwater Research and Engineering Station Technical Memorandum No. $396,33 \mathrm{pp}$. 
National Academy of Sciences. 1973. Background Papers for a Workshop on Inputs, Fates, and Effects of Petroleum in the Marine Environ., Vo1. 1. Washington, D.C., 374pp.

National Academy of Sciences. 1975. Petroleum in the Marine Environment, Workshop on Inputs, Fates, and the Effects of Petroleum in the Marine Environment, Washington, D.C., 107pp.

Ne1son, W.L. 1978. Will Tube refiners reclaim waste oils? 0il and Gas Journa1 76(20), 75-76.

Oviatt, C.A., Nixon, S.W. 1975. Sediment resuspension and deposition in Narragansett Bay. Est. Coastal Mar. Sci. 3, 201-217. Porricel1i, J.D., Keith, V.F., Storch, R.L. 1971. Tankers and the ecology. Trans. Soc. Nav. Arch. Mar. Eng. 79,196-221. Premack, J., Brown, G.A. 1973. Predictions of oil slick motions in Narragansett Bay. In Proceedings of Joint Conference on Prevention and Control of 0i1 Spil1s, 5531-5540.

Rhoads, D.C. 1974. Organism-sediment relations on the muddy sea floor. Oceanogr. Mar. Biol. Ann. Rev. 12, 263-300.

R. I. Department of Health, Division of Water Supply and Pollution Control. 1975. Listing of discharges to accompany present water quality condition map.

Schenk, H., Davis, A. 1973. A turbidity survey of Narragansett Bay. Ocean Engineering 2 2 , 169-178.

Schultz, D.M. 1974. Source, Formation, and Composition of Suspended Lipoidal Material in Narragansett Bay, Rhode Island. Ph.D Thesis, Univ. of R. I., 205pp. 
Schultz, D.M., Quinn, J.G. 1973. Fatty acid composition of organic detritus from Spartina alterniflora. Est. Coastal Mar. Sci. 1, $71-79$.

Schultz, D.M., Quinn, J.G. 1977. Suspended material in Narragansett Bay: fatty acid and hydrocarbon composition. Org. Geochem. I, $27-36$.

Shaw, D.G. 1973. Lipids in shallow bottom sediments. Environ. Sci. Technol. 7, 740-742.

Sutterlin, A.M. 1974. Pollutants and the chemical senses of aquatic animals perspective and review. Chem. Senses and Flavour I, 167-178. Thompson, S., Eglinton, G. 1978. The fractionation of a Recent sediment for organic geochemical analysis. Geochim. Cosmochim. Acta 42, 199-207.

U.S. Coast Guard. 1975. Polluting incidents in and around U.S. waters, 1974. USCG (G-WEP). Washington, D.C., 16pp.

U.S. Coast Guard. 1976. Polluting incidents in and around U.S. waters, 1975. USCG (CG-487). Washington, D.C., 24pp.

Van Vleet, E.S., Quinn, J.G. 1977. Input and fate of petroleum hydrocarbons entering the Providence River and Upper Narragansett Bay from wastewater effluents. Environ. Sci. and Technol. 11, 1086-1092.

Van Vleet, E.S., Quinn, J.G. 1978. Contribution of chronic petroleum inputs to Narragansett Bay and Rhode Island Sound sediments. 3. Fish. Res. Board Can. 35, 536-543. 
Wade, T.L., Quinn, J.G. 1978a. Geochemical distribution of hydrocarbons and chlorinated hydrocarbons in sediments from Narragansett Bay, R.I. To be submitted to org. Geochem. Wade, T.L., Quinn, J.G. 1978b. Incorporation, distribution, and fate of saturated petroleum hydrocarbons in sediments from a controlled marine ecosystem. To be submitted to Environ. Pollut. Wakeham, S.G. 1976. A comparative survey of petroleum hydrocarbons in lake sediments. Ilar. Pollut. Bull. 7, 206-211. Wakeham, S.G. 1977. Synchronous; fluorescence spectroscopy and its application to indigenous and petroleum-derived hydrocarbons in lacustrine sediments. Environ. Sci. Technol. 11, 272-276, Wakeham, S.G., Carpenter, R. 1976. Aliphatic hydrocarbons in sediments of Lake Washington. Limnol. Oceanogr. 21, 711-723. Walker, J.D., Colwe11, R.R., Ford, H.T. 1975. Petroleum hydrocarbons of Chesapeake Bay: distribution in sediment cores. Environ. Pollut. 9, 231-238.

Wegener, P.T. 1973. $0 i 1$ pollution in Baltimore Harbour. M.S. Thesis. John Hopkins Univ., Baltimore, MD.

Weisberg, R.H., Sturges, W. 1973. The net circulation in the West Passage of Narragansett Bay. Univ. of Rhode Island Technical Report 3-73, 96pp.

Youngblood, W.W., Blumer, M. 1975. Polycyclic aromatic hydrocarbons in the environment: homologous series in soils and recent marine sediments. Geochim. Cosmochim. Acta 39, 1303-1314.

Zafiriou, 0.C. 1973. Petroleum hydrocarbons in Narragansett Bay, II. Chemical and isotopic anatysis. Est. Coastal Mar. Sci. I, $81-87$. 
APPENDIX I

$\mathrm{HC}_{344}$ in Mercenaria mercenaria Fecal Material

Mercenaria mercenaria from two areas of Narragansett Bay were obtained from the Department of Natural Resources in September, 1977 to determine the relative concentration of $\mathrm{HC}_{344}$ in fecal material from this organism. The clam samples were taken from a "polluted" area (Greenwich Cove, GC) which is affected by sewage effluent and boating activities. This is a restricted shellfishing area, and shellfish must depurate before being consumed. The other sampling station was off of Mount View and considered a "clean" area (MV).

Approximately one bushel from each station was collected and taken to separate holding tanks at the Graduate School of Oceanography Aquarium Building with running seawater from Narragansett Bay. The clams were suspended enough off the bottom to insert glass trays underneath to obtain fecal material which was collected for a period of about one month.

There was a noticeable difference between the clams: those from the stressed area were smaller and the shells were whiter than those from the clean area. Whether or not this was due to the sampling or was real is not clear.

After collection of the fecal material, the samples were centrifuged to remove as much water as possible, and subsamples were taken for a moisture determination. The moisture values were approximately equal to or higher than those for the sediments. The balance of the procedure follows that described in the Materials and Methods 
section.

The results in Table 1 indicate that the concentration of $\mathrm{HC}_{344}$ in the fecal material (which includes some sediment) is not substantially higher than in the surface sediments. Also, the total hydrocarbon concentrations for both samples were essentially the same. Sediment samples were not collected at the same sites as the clams. However, there were some sediment cores taken in close proximity to GC and MV, GB and station 7 respectively. The surface values are shown in Table 1 to compare to those of the fecal material. Percent moisture for GB was slightly higher than for GC while MV had a higher water content than station 7. In both cases the total hydrocarbon values for the fecal material were lower than for the sediments. Also, the percent resolved hydrocarbons are higher for the feces than for the sediment. Furthermore, there was no trend in the biogenic hydrocarbon concentration between the sediments and the fecal material. GC was higher in $\mathrm{HC}_{344}$ than GB, and station 7 was higher than MV.

At the outset it was hoped that this experiment would reveal that Mercenaria mercenaria fecal material was concentrated in $\mathrm{HC}_{344}$, and was therefore a source of this component in the sediments. However, from the 1 imited results it appears that this is not the case. 
Table 1. Comparison of hydrocarbon analyses of surface sediments $(0-5 \mathrm{~cm})$ and fecal material from Mercenaria mercenaria. 


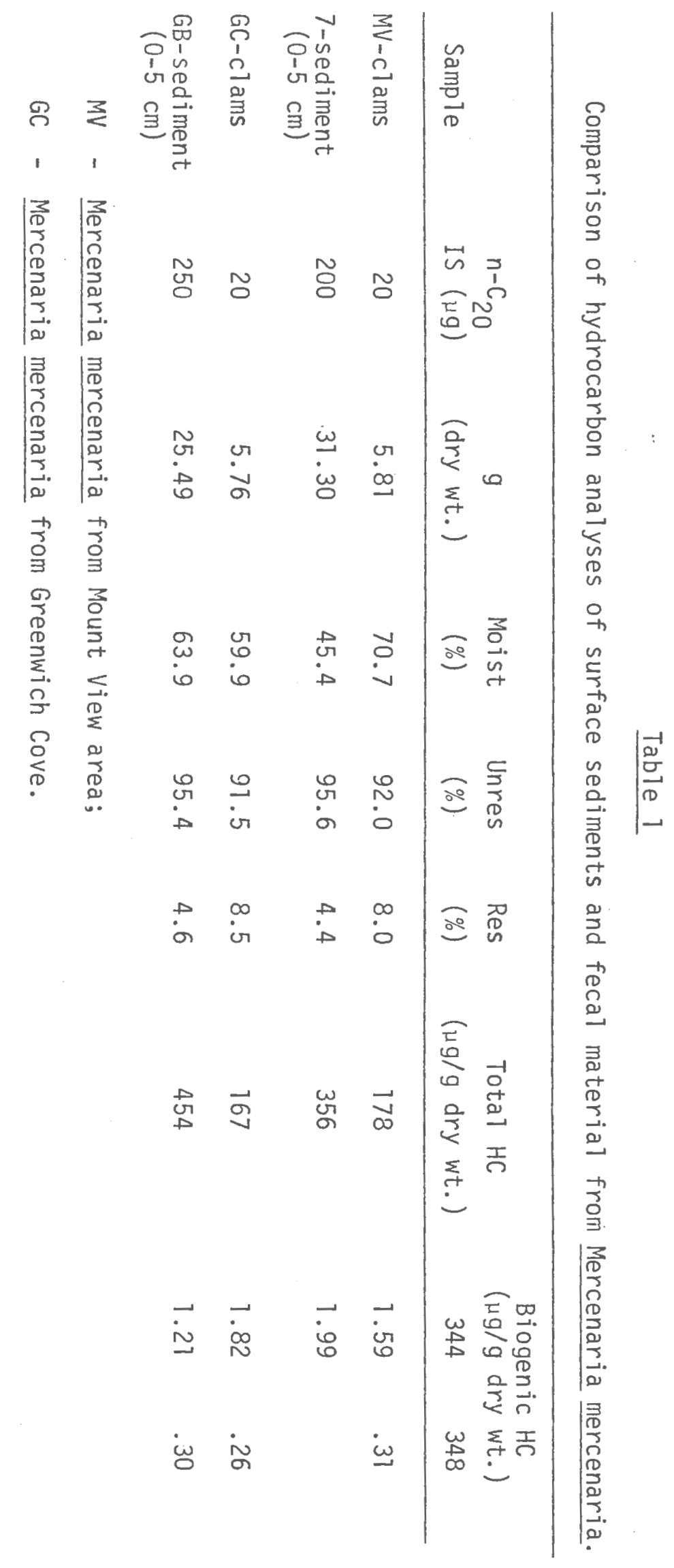


APPENDIX II 
Table 1. Compendium of hydrocarbon data from twenty sediment cores in Narragansett Bay. 


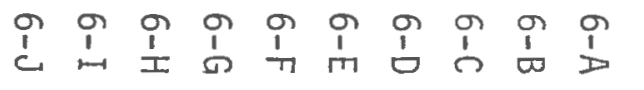

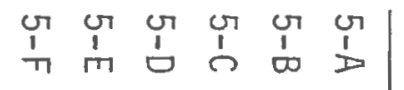

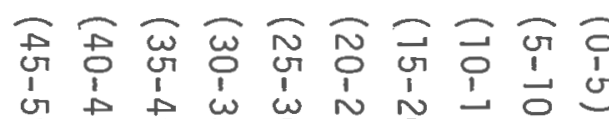

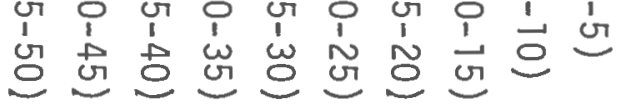

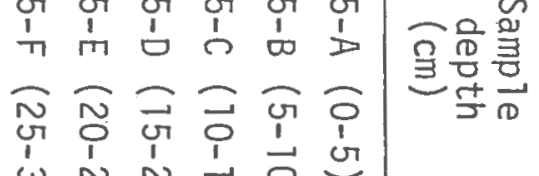

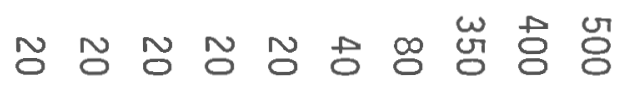

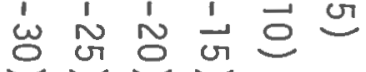

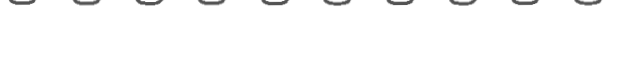

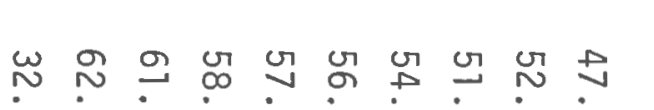

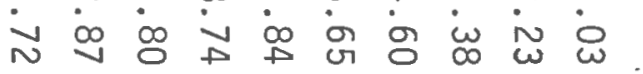

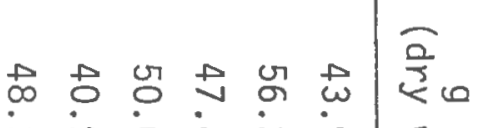

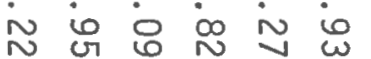

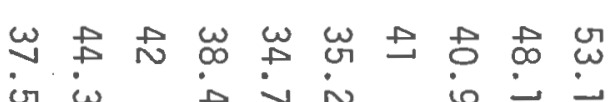

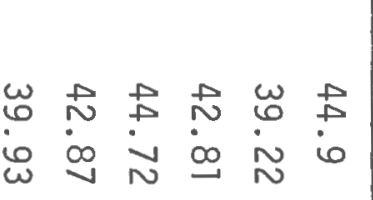

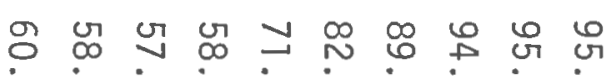

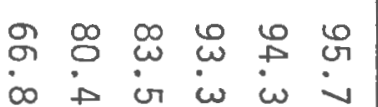

จำ

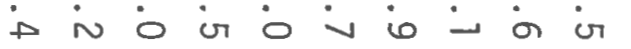

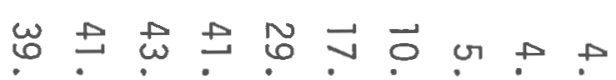

$\omega \overrightarrow{0} \vec{\sigma} \sigma$ or

or $\infty$ io ir i i $\rightarrow$ io ir

iv o ir viv

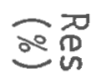

or $u$ r

$\dot{\omega} \dot{0} \dot{\omega} \dot{0}$ o i

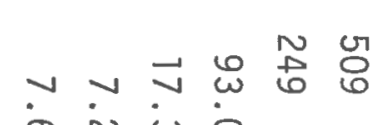

居

启

0
0
0
0
0

$\sum_{\frac{2}{2}}^{\frac{1}{2}}$

$\sum_{+}^{+}$

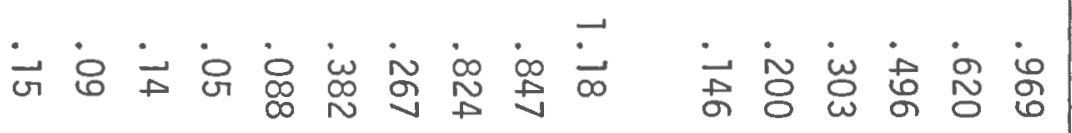

$\widehat{\tau} \omega \varpi$

$\underbrace{\circ}_{0}+\frac{0}{0}$

高 $\stackrel{n}{3}$.

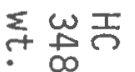

$\infty \vec{N} \vec{\omega} \overrightarrow{0} \vec{\omega} \vec{\sim} \tilde{O} \vec{\sigma} \vec{\sigma} \vec{\omega} \tilde{\omega}$

急

$\notin$ or 


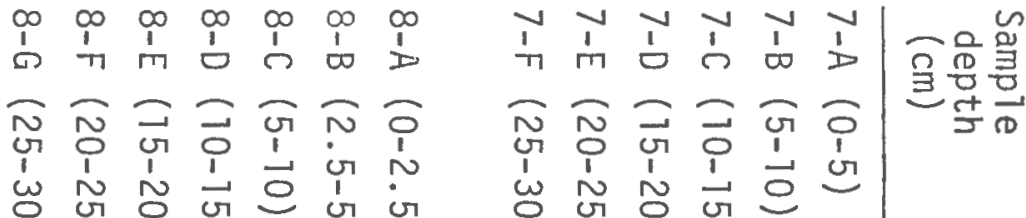

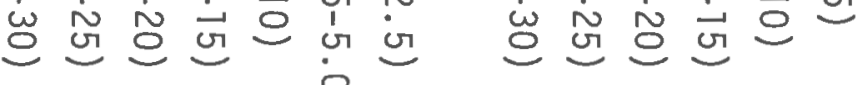

$$
\begin{aligned}
& \text { 을 } \\
& \text { స }
\end{aligned}
$$

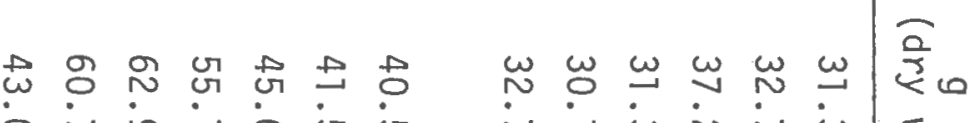

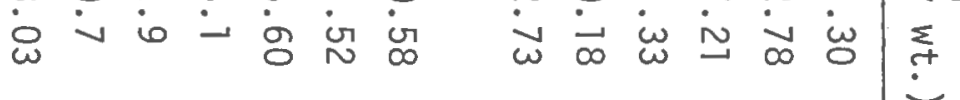

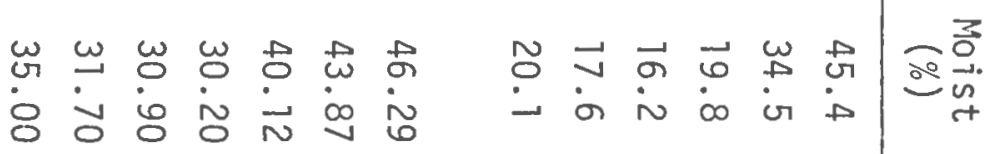

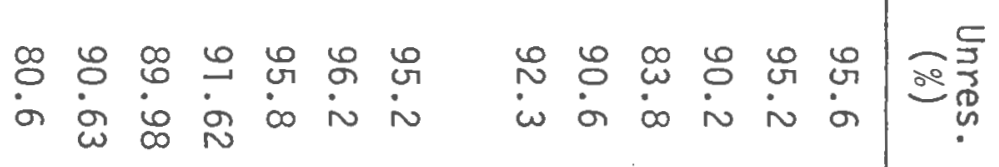

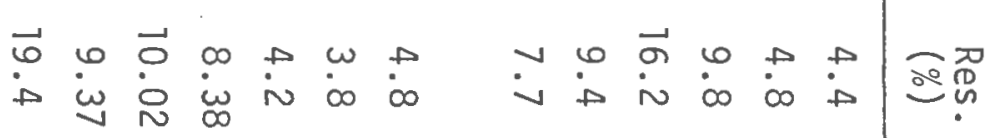

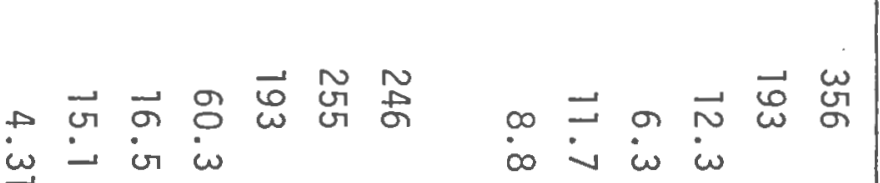

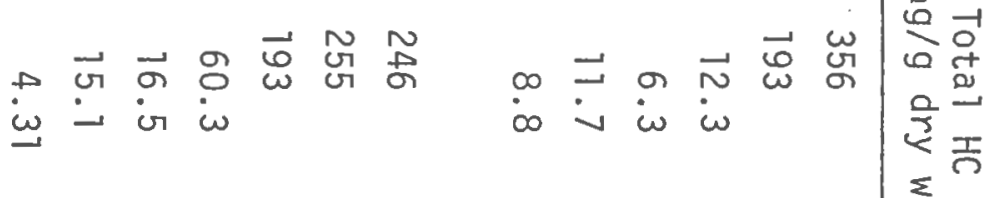

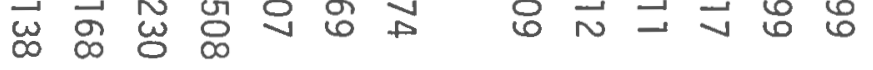

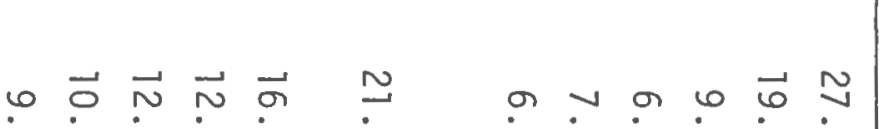

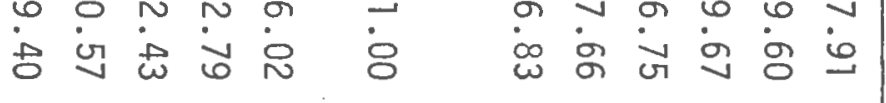

$$
\begin{aligned}
& \text { ᄅे } \\
& \stackrel{\sum_{+}^{+} \omega}{+} \underset{\infty}{+} \\
& \text { 䯧 } \\
& \stackrel{\sum_{+}^{+}}{\longleftarrow}
\end{aligned}
$$




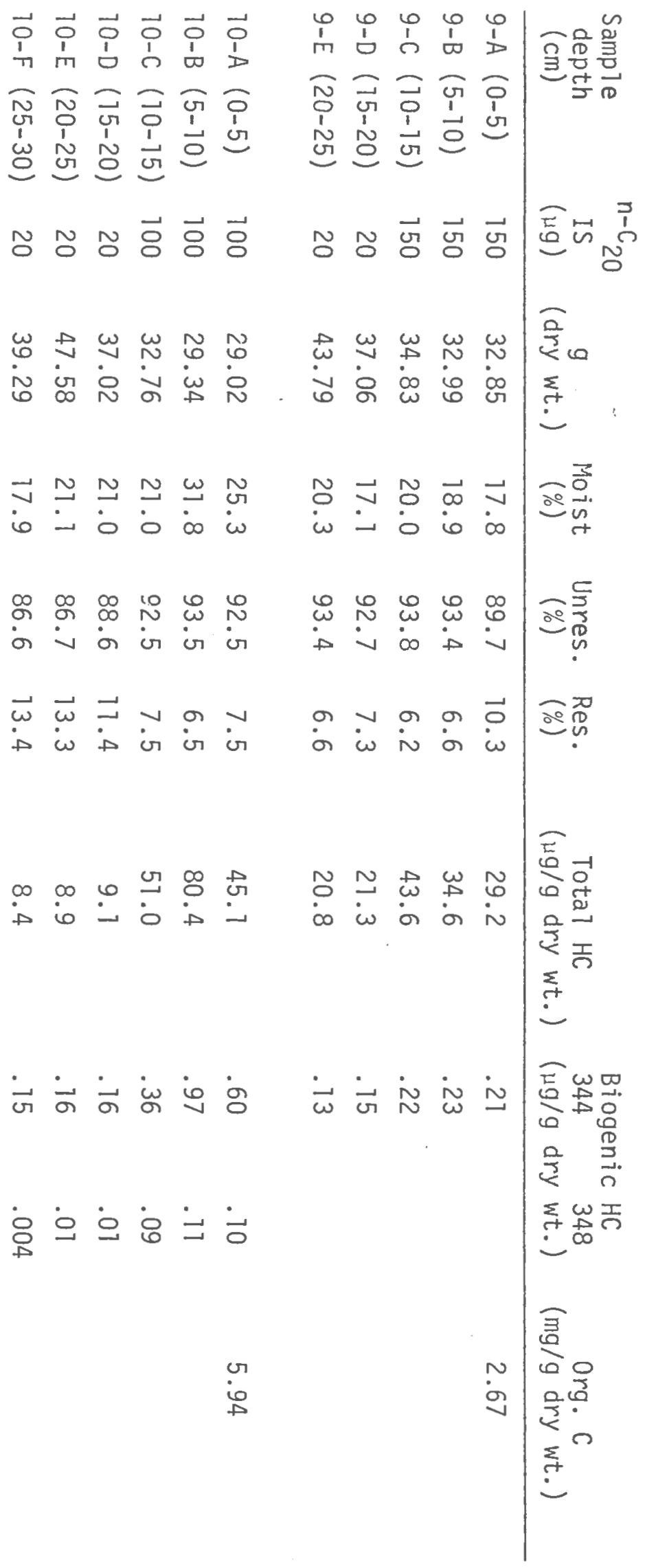




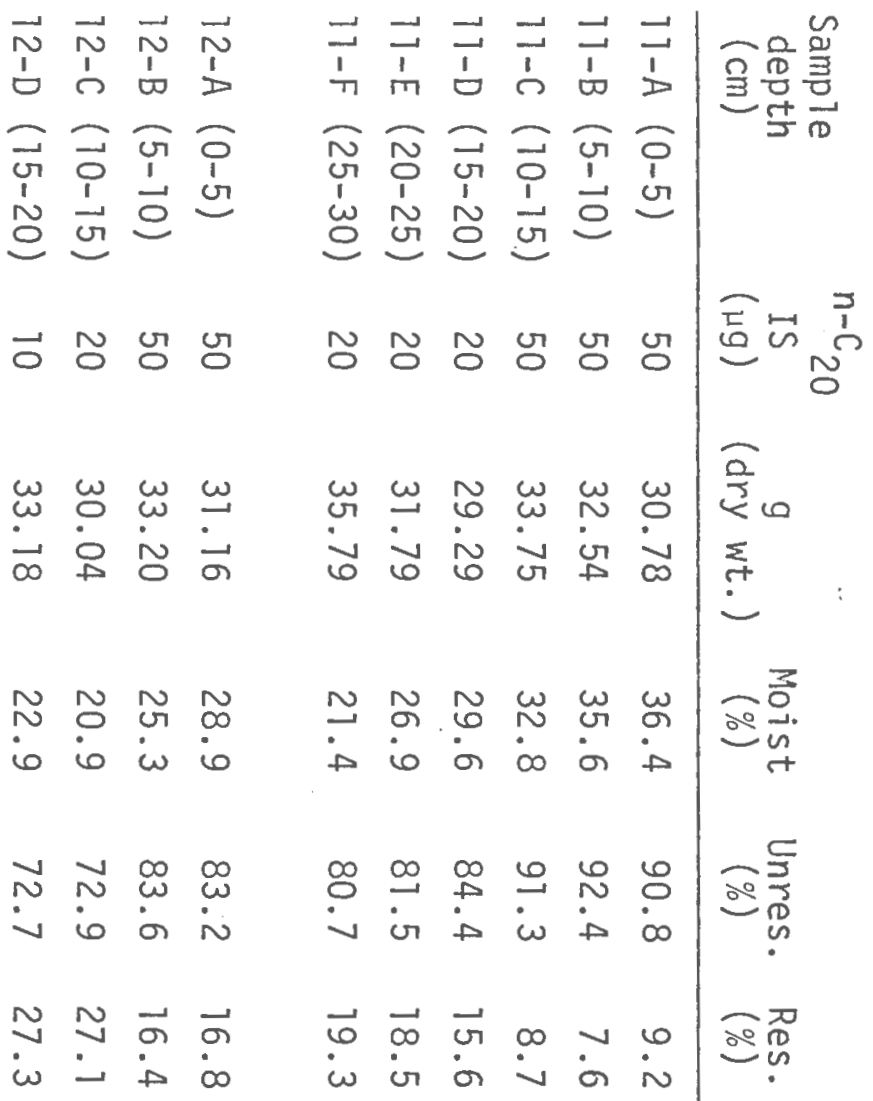

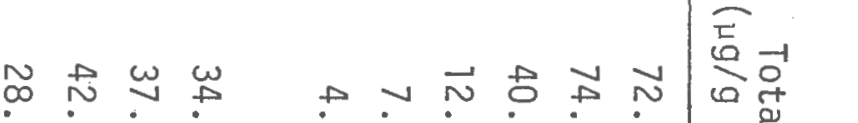

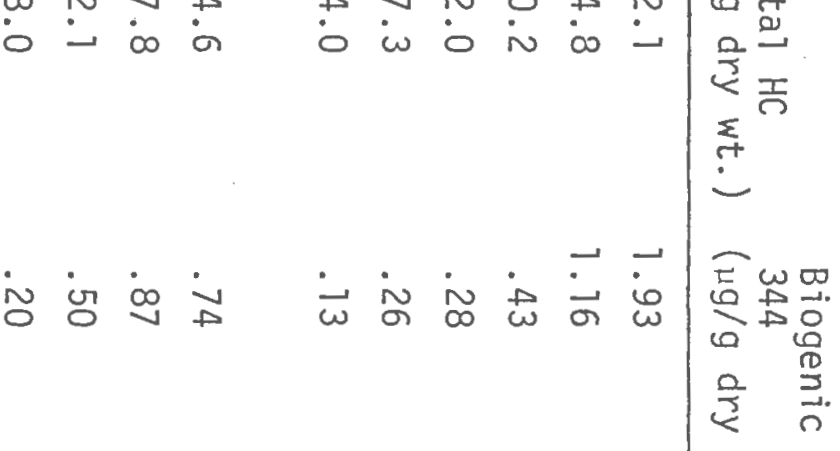

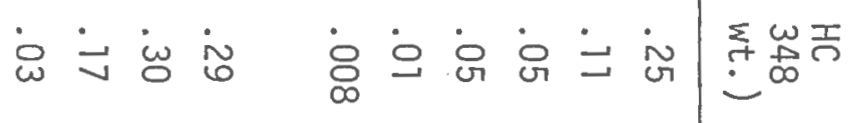

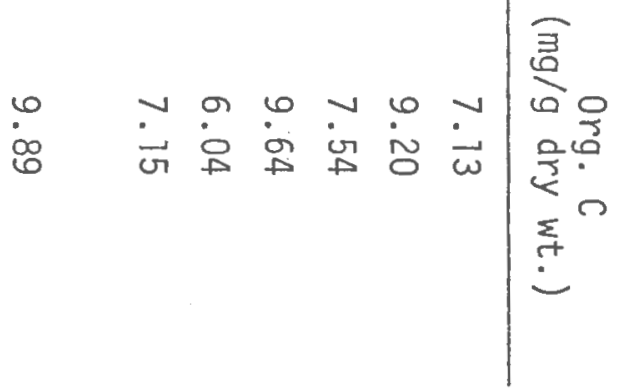




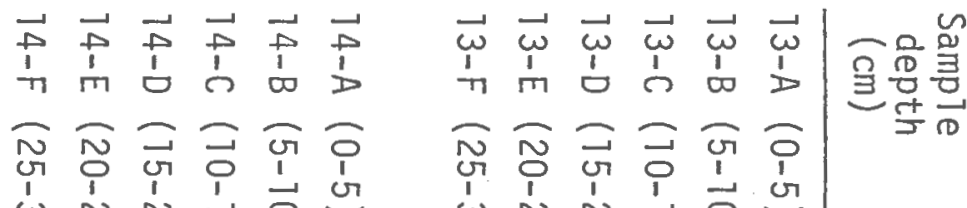

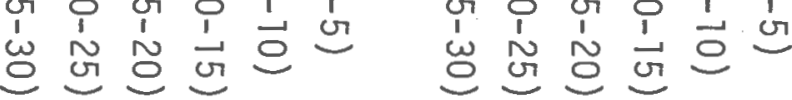

$\vec{\circ} \vec{\circ} \vec{\circ} \vec{\circ} \vec{\circ} \vec{\circ} \vec{\circ}$ 용

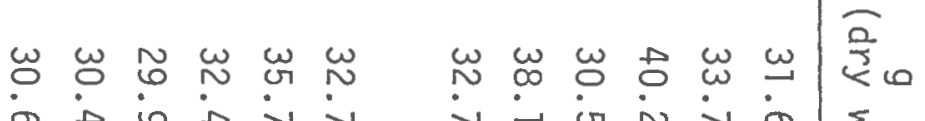
g में

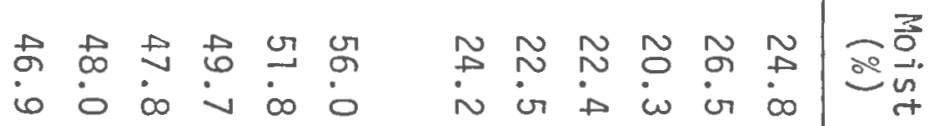

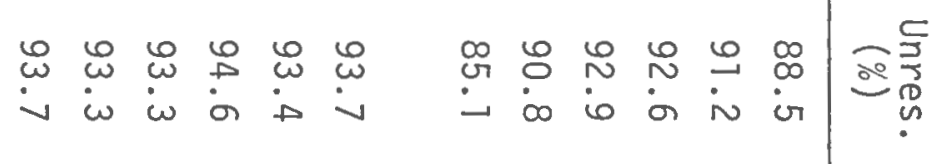

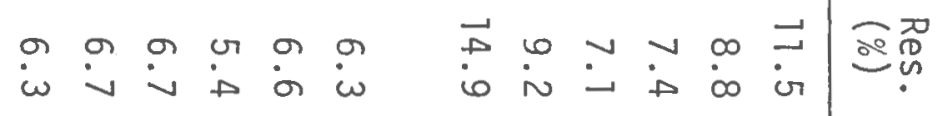

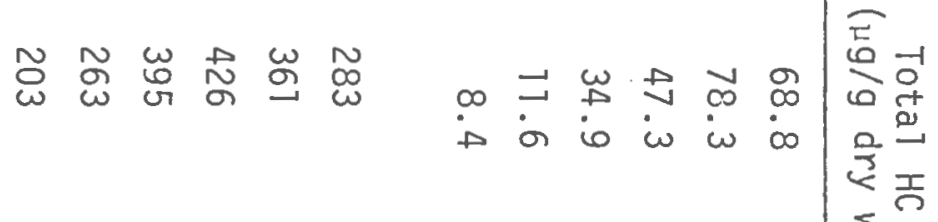

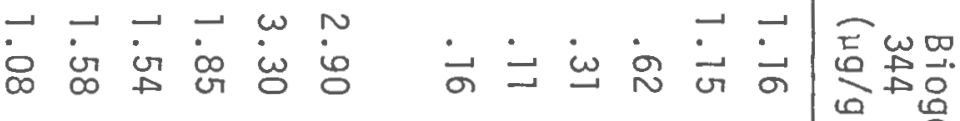

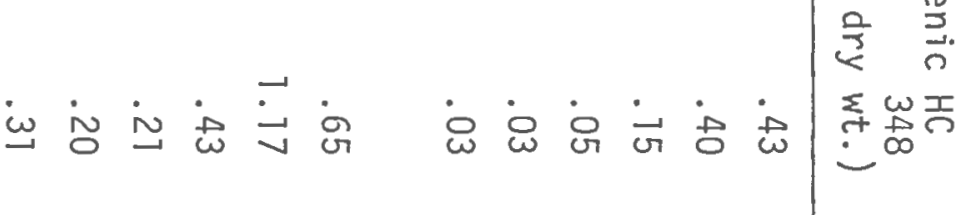

$\dot{\infty}$

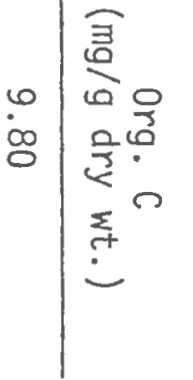




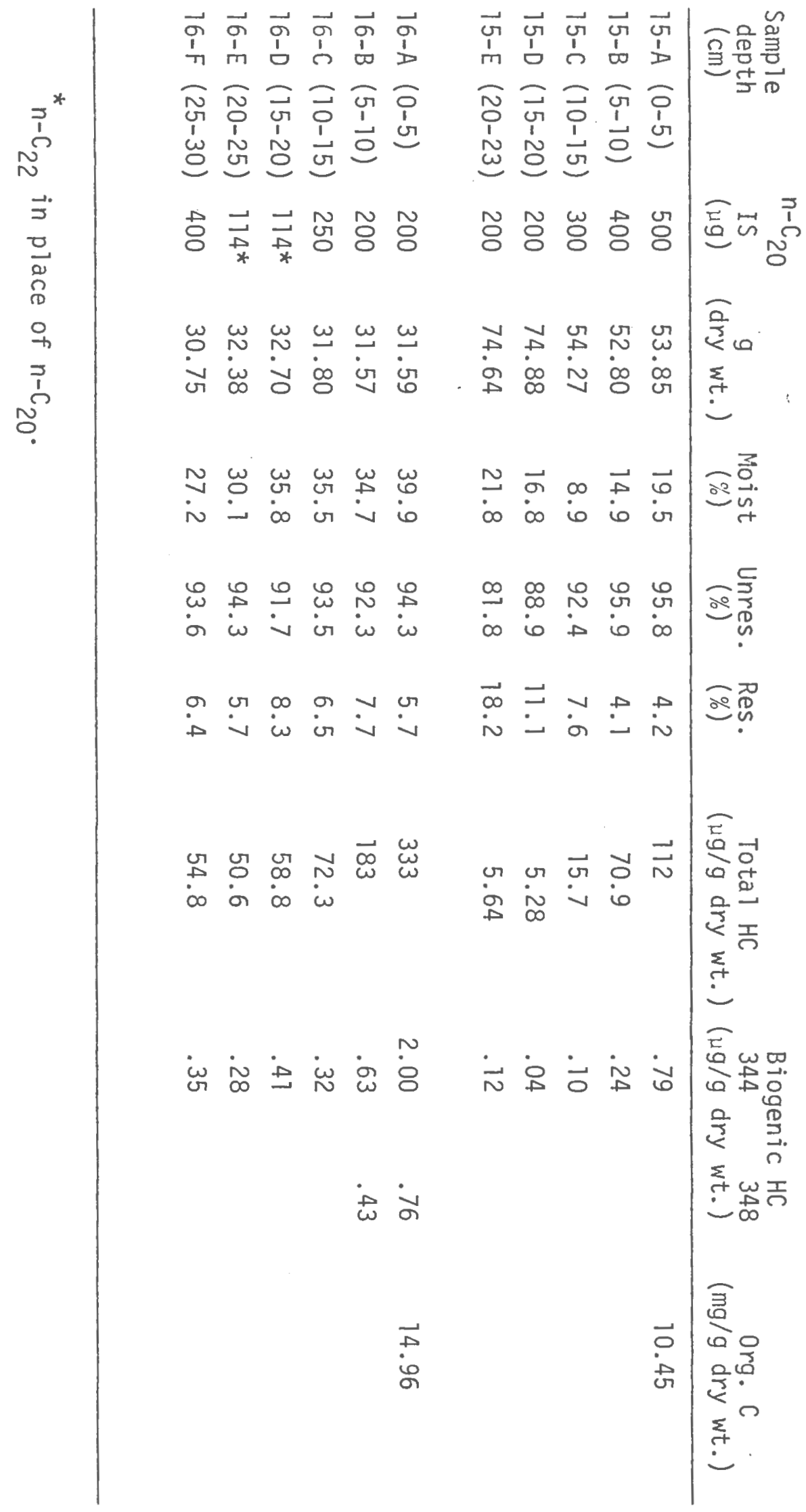




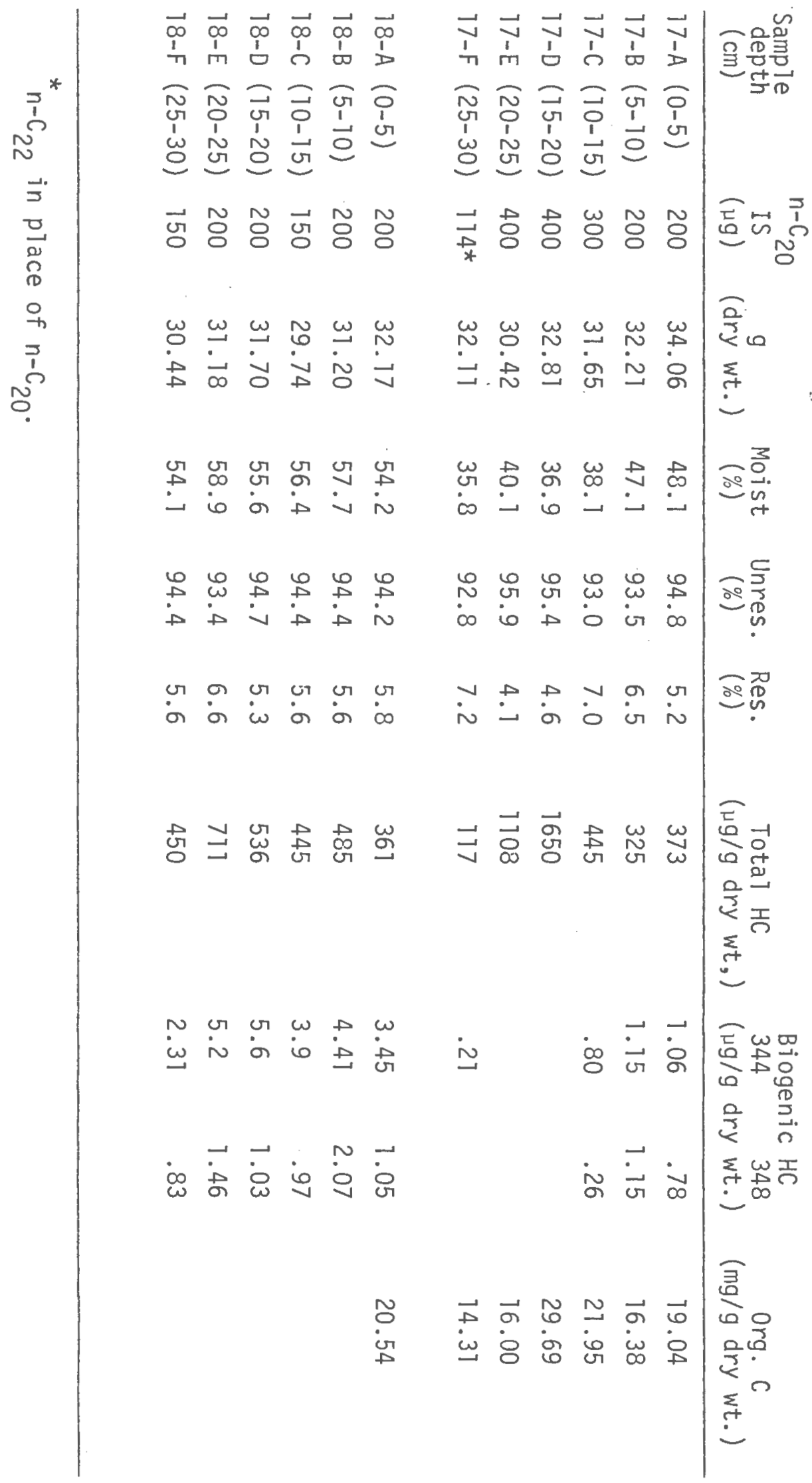




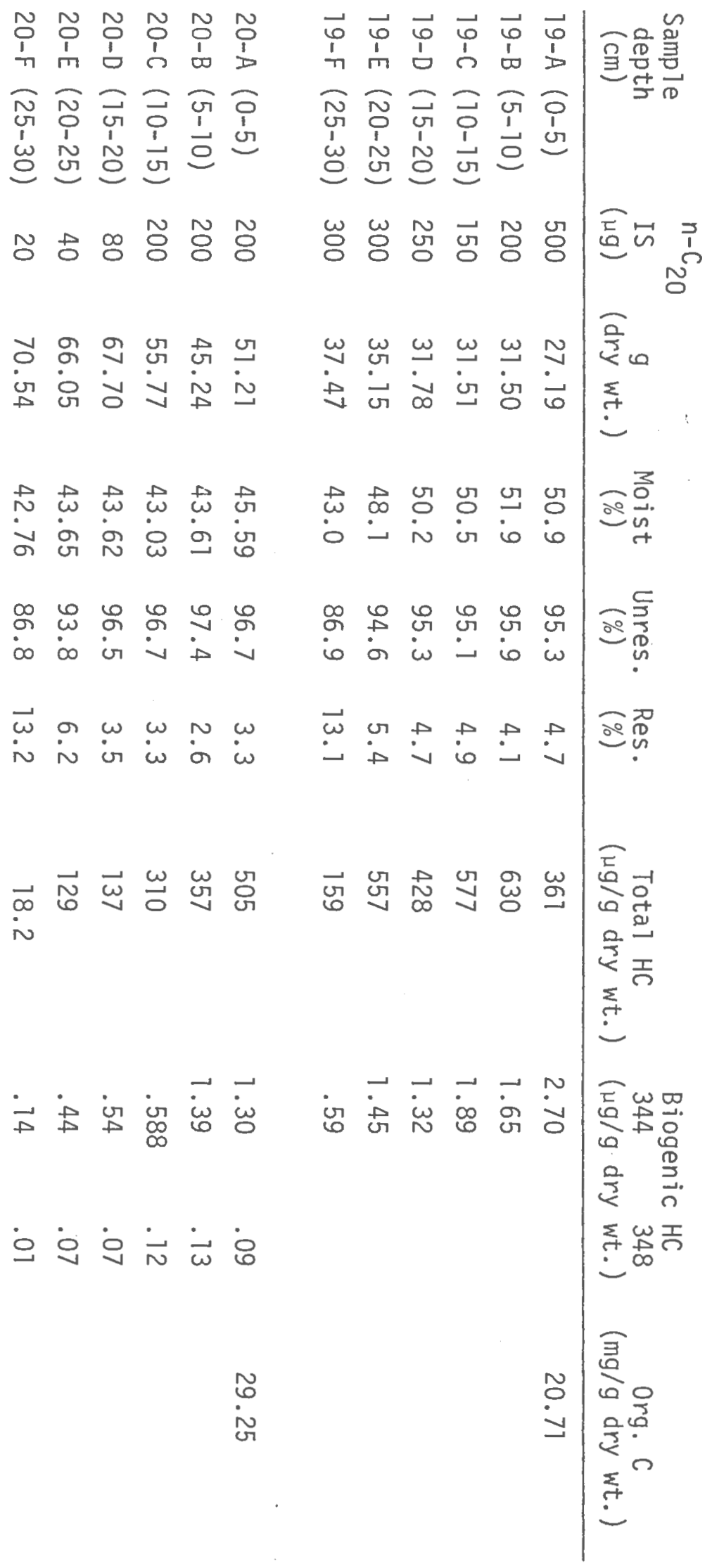




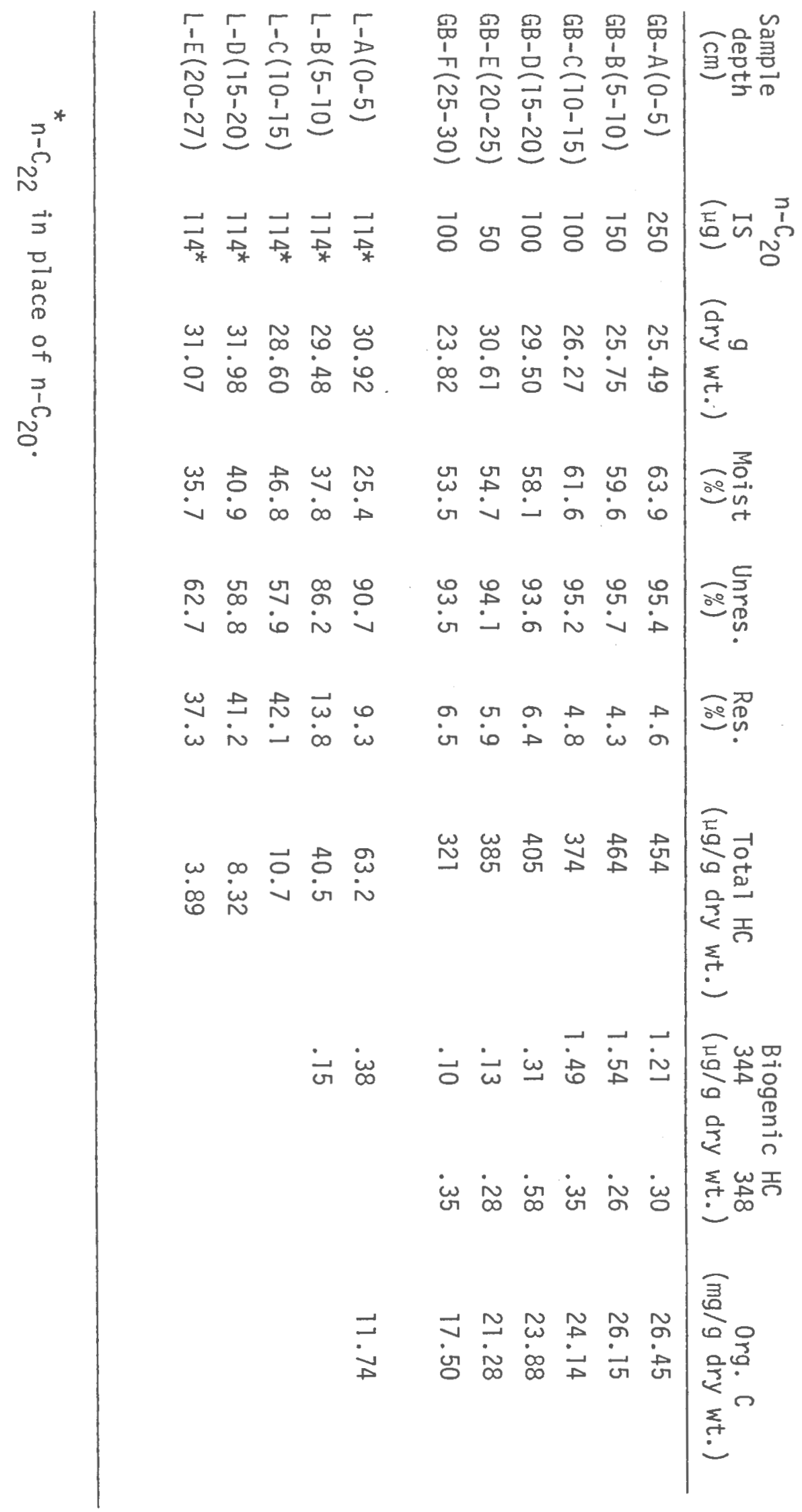



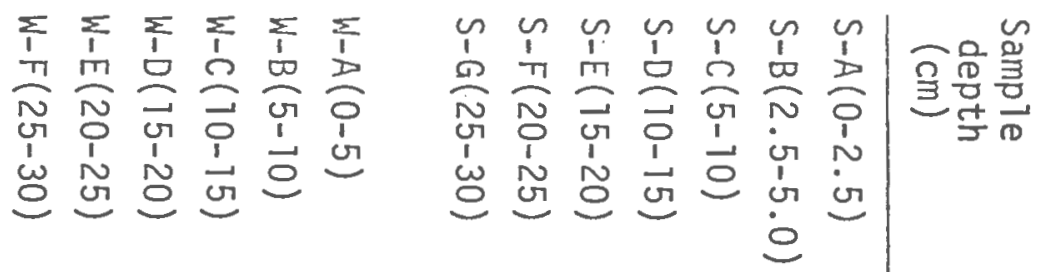

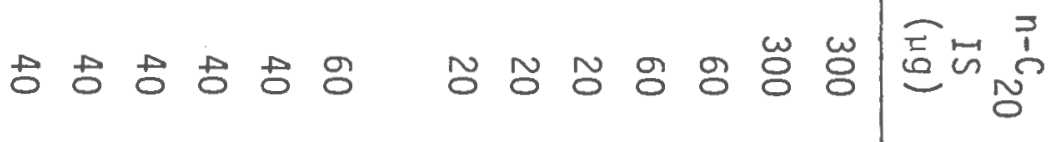

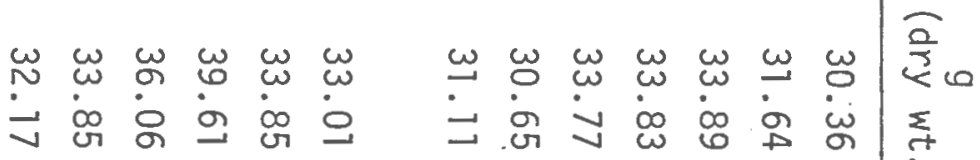

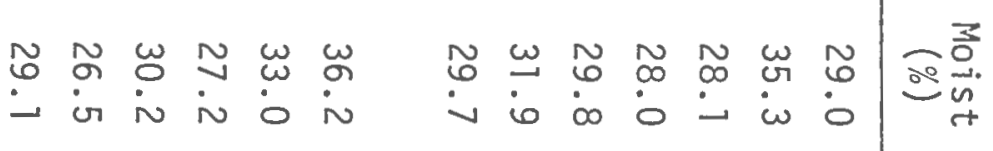

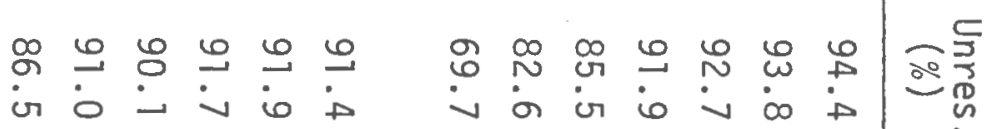

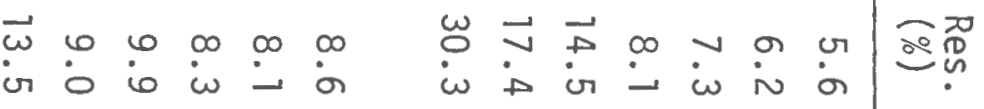

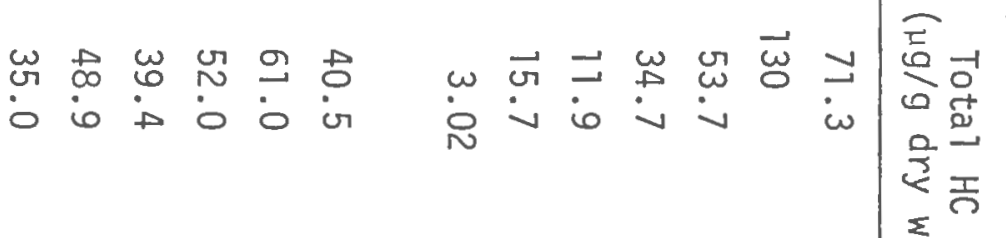

$\dot{\sim} \dot{\sigma} \dot{\tilde{\omega}} \dot{\sim} \dot{\sim} \dot{\alpha}$

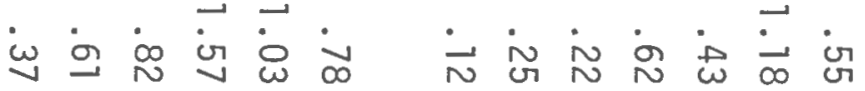

总出

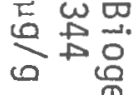

疍

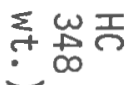

$\ddot{0}$

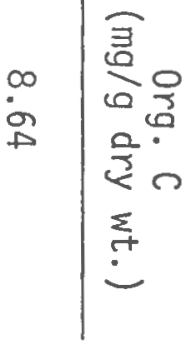

